\title{
La "guerra" en la jurisprudencia de la Corte Interamericana de Derechos Humanos
}

Fecha de recepción: 6 de noviembre de 2009

Fecha de aceptación: 26 de marzo de 2010

\section{Laurence Burgorgue-Larsen ${ }^{*}$ y Amaya Úbeda de Torres ${ }^{* *}$}

Resumen: ¿De qué manera los órganos del sistema interamericano de derechos humanos han hecho frente a la noción de "guerra", concepto que ha ido cambiando con el tiempo, siendo la expresión utilizada hoy la de "conflicto armado", ya sea interno o internacional? Esta pregunta se halla a la base del análisis desarrollado en la primera parte de este artículo, demostrando que el continente americano ha sido objeto de conflictos de todo tipo. La heterogeneidad de situaciones (conflictos armados, tensiones internas, terrorismo de Estado) ha engendrado una variedad de calificaciones jurídicas que tanto la Comisión como la Corte interamericanas han identificado con detalle en su jurisprudencia. Esta operación de conceptualización es aún más trascendente por su implicación para el Derecho Internacional aplicable a los conflictos armados. A través de este estudio, resurge el eterno debate de la relación entre dos ramas clave del Derecho internacional: la del Derecho Internacional de los Derechos Humanos y la del Derecho Internacional Humanitario. La segunda parte del análisis tiene por objeto explorar, pues, si el ius in bello ha encontrado su sitio en la jurisprudencia de los órganos del sistema interamericano de derechos humanos. En fin, los cambios que han acompañado buena parte de la historia política del continente americano demuestran igualmente la importancia de tener en cuenta el régimen apli-

\footnotetext{
* Laurence Burgorgue-Larsen es Catedrática en la Facultad de Derecho de la Sorbona (Universidad Paris I) y Co-directora del "Institut de Recherche en Droit international et Européen de la Sorbonne” (IREDIES).

** Amaya Úbeda es Investigadora García Pelayo del Centro de Estudios Políticos y Constitucionales de Madrid..
} 
cable a los estados de excepción, muy presente en el trabajo de la Corte y la Comisión Interamericanas.

Palabras claves: Guerra, Derecho Internacional Humanitario, conflicto armado, jurisprudencia, Corte Interamericana, Comisión Interamericana, terrorismo de Estado, disturbio interno, estado de excepción.

Summary: How have Inter-American Human Rights bodies dealt with the notion of "war", which has been transformed over time into the notion of internal and international "armed conflicts"? This question provides the analytical foundation of the first part of this study, which sets out the various types of conflicts that have occurred in the American continent. These situations (armed conflicts, internal strife, State terrorism) have produced a wide range of legal categorizations, utilized by both the Commission and Inter-American Court of Human Rights in their case-law. This conceptual delimitation carried out by these two bodies is all the more important as it affects the law that applies to armed conflicts. Indeed, by analysing this question, the never-ending debate on the relationship between International Human Rights Law and International Humanitarian Law reappears. The second part of this study therefore focuses on the issue of discovering whether and in which way jus in bello has found its place into the Inter-American Human Rights bodies' case-law. As the active political life of Latin American societies has shown, the study of the different applicable legal regimes also requires looking into "state of emergency" Law, an issue which has been shaped by the Inter-American Court and Commission's work.

Key words: War, International Humanitarian Law, internal conflict, jurisprudence, Interamerican Court, Interamerican Comission, State terrorism, internal disturbances, state of exception.

Resumé: De quelle manière les organes du système interaméricain ont-ils appréhendés la «guerre», dont on sait qu'elle s'est métamorphosée au fil du temps en «conflits armés» - tantôt internes, tantôt internationaux? Cette première interrogation irrigue les développements de la première partie de cet article qui montre que le continent latino-américain a été le terreau de conflits de tout type. Cette hétérogénéité des situations (conflits armés, troubles internes, terrorisme d'Etat) a engendré une variété des qualifications juridiques que la Commission comme la Cour interaméricaine ont bien identifiées dans leur jurisprudence. Cette opération de délimitation conceptuelle est d'autant 
plus importante qu'elle conditionne le droit applicable aux conflits. Or, en abordant cette thématique, c'est l'éternel problème de l'interconnexion entre deux grandes branches du droit international (les droits de l'homme et le droit international humanitaire) qui resurgit. La deuxième partie de l'article a ainsi pour objet de décrypter la question de savoir si et dans quelle mesure le jus in bello a sa place dans la jurisprudence des organes du système interaméricain des droits de l'homme. Toutefois, la vie politique mouvementée des sociétés latino-américaines démontre également que la problématique du droit applicable aux «régimes d'exception» est une question centrale traitée à bras le corps par la Commission et la Cour interaméricaine.

Mots Clés: Guerre, droit international humanitaire, conflit armé, jurisprudence, Cour Interaméricaine, Commission Interaméricaine, terrorisme d'État, désordres intérieures, état d'exception.

La metamorfosis de los conflictos y enfrentamientos que se han producido a lo largo del siglo XX ha sido de tal magnitud que el concepto de guerra, latente en la mayor parte de los instrumentos internacionales existentes en la época de entre guerras, ${ }^{1}$ ha cedido su protagonismo en favor del concepto, más amplio, de "conflicto armado". 2 Si el siglo XX ha sido el escenario de cambios radicales, el XXI confirma la propagación de los desórdenes geopolíticos.

La era de la hegemonía ejercida por los Estados Unidos ${ }^{3}$ ha sucedido al orden bipolar de la Guerra Fría; los conflictos armados internos priman sobre las clásicas guerras entre Estados, ${ }^{4}$ hasta el punto de que la política del terror ha invadido todos los recovecos del "pueblo planetario", 5 haciendo

1 Por ejemplo, los artículos 11-13, 15-16 del Pacto de la Sociedad de Naciones y el artículo $1^{\circ}$ del Pacto Briand-Kellog.

2 Resulta sintomático constatar la proliferación de estudios no centrados en la "guerra", sino en las "crisis", ver Dufour, J-L. Les crises internationales. De Pékin (1900) à Bagdad (2004). Paris : Ed. Complexes, 2004, 326 p.; ver también la obra clásica del ex presidente del Tribunal Internacional de Justicia, Gilbert Guillaume, Les grandes crises internationales et le droit. Paris: Seuil, 1994, 318 p. (Coll. Point Essais).

3 El "Estado hegemón", en palabras del profesor Antonio Remiro Brótons.

4 Ver sobre el término guerra las entradas existentes en el diccionario clásico del profesor Salmon, J. Dictionnaire de droit international public. Bruxelles : Bruylant, 2001, p. 538.

5 Hasta los rascacielos neoyorquinos: el ataque a las Torres Gemelas ha colocado a los Es- 
tambalearse incluso a los órdenes más estables y abriendo paso a los oscurantismos de toda clase y condición.

El continente americano no ha escapado a esta transformación radical de las relaciones internacionales, sino que ha quedado, por así decirlo, ligado a estas formas contemporáneas de "guerras": las guerrillas, las contraguerrillas, las guerras civiles, el terrorismo de Estado... son elementos tanto del pasado como del presente en ciertos países del hemisferio sur.

La utilización de la fuerza armada y/o del terror por parte del Estado y/o de un grupo de personas (privadas o apoyadas por las instancias estatales), con el objetivo, a menudo, de imponer un régimen político autoritario y de hacer callar a las personas consideradas como "subversivas", ha constituido una parte de la historia de numerosos países del continente y sigue todavía (sobre todo en Colombia) amenazando el desarrollo y el asentamiento de la democracia. Estas situaciones extremas en el seno de las Américas han tomado a menudo impulso sobre terreno abonado por "crisis internas" que han llevado a algunos gobiernos a tomar medidas de excepción, tristes premisas que sirvieron para que se asentasen regímenes represores de la libertad.

tados Unidos en una posición difícil y contradictoria, al reconocer que estaban en "guerra", pero que, sin embargo, no reconocerían el estatuto de "tropas regulares" a los combatientes de Al Qaeda; ver Andreani, G. La guerre contre le terrorisme. Le piege des mots. AFRI, 2003, pp. 102-114; ver Pérez González, M. \& Rodríguez-Villasante, J-L. El caso de los detenidos de Guantánamo ante el derecho internacional humanitario y de los derechos humanos. Revista Española de Derecho Internacional, 54(1), 2002, pp. 11-40. Para todas las preguntas que en Derecho Internacional plantea el terrorismo de masas, ver Bannelier, K.; Christakis, T.; Corten, O. \& Delcourt, B. (dirs.). Le droit international face au terrorisme. Paris : Pedone, 2002, 356 p. (Col. Cahiers internationaux du Cedin Paris I, $\mathrm{n}^{\mathrm{a}}$ 17). Todo ello sin tener en cuenta la jurisprudencia de la Corte Suprema de los Estados Unidos, que ha rebatido tal interpretación en la muy importante decisión del 12 de junio del 2008, Boumedienne v. Bush, na 06-1195 (ver Duffy, H. Human rights litigation and the "war of terror". Revue internationale de la Croix Rouge, 80(871), septiembre 2008, pp. 573-597). Este asunto se sitúa en el núcleo de sus decisiones del 2004 y 2006, que el Congreso, en manos de los neoconservadores, había sistemáticamente tratado de soslayar. Las dos primeras decisiones del 2004 consideraban que tanto los "combatientes enemigos" (ciudadanos americanos detenidos en el curso de la guerra contra el terrorismo) como los "combatientes irregulares" (detenidos no americanos) debían tener la posibilidad de acceder a la justicia civil americana. Ver Corte Suprema de los Estados Unidos, 28 de junio del 2004, Hamdiv. Rumsfeld, na 03/6696: Corte Suprema de los Estados Unidos, 28 de junio del 2004, Rasulv. Bush, na 03/334. Para tener una visión global de la postura de los Estados Unidos con respecto a la justicia internacional, ver Bourgorgue-Larsen, L. Les Etats Unis d'Amérique et la justice internationale. Entre l'utilisation et l'instrumentalisation du Droit International. In : Ben Achour, R. \& Laghmani, S. (dirs.). Le Droit International a la croisée des chemins. Force du droit et force de la force. Paris: Pedone, 2004, pp. 233-269. 
Esta heterogeneidad de las manifestaciones de la violencia y sus vínculos, a veces cercanos y a veces lejanos, con la "guerra", demuestran que la naturaleza de los conflictos es un tema central cuando se pretende ofrecer una explicación, aunque sea breve, de la jurisprudencia interamericana en esta materia (I). Una vez realizada la sistematización de los diferentes tipos de situaciones conflictivas a las que se han enfrentado los órganos del sistema interamericano, será posible evaluar la posición de la Comisión y de la Corte Interamericanas acerca del derecho aplicable a esos conflictos (II).

\section{La naturaleza múltiple de los conflictos}

La Corte Interamericana ha tenido, como es lógico, que examinar asuntos donde los estigmas de una violencia radical, procedente tanto de personas privadas como de agentes del Estado, han roto la paz civil de numerosas sociedades del continente americano, organizando matanzas, desapariciones forzadas, ejecuciones extrajudiciales y torturas. El primer obstáculo al que se ha enfrentado la Corte ha sido el de identificar los distintos tipos de conflictos, de naturaleza particularmente difícil, a veces imposible, sobre los que ha debido de pronunciarse. Esta identificación se convierte en algo aún más crucial si se tiene en cuenta la instrumentalización política de los términos "guerra", "conflicto armado" o incluso "estado de urgencia" por parte de algunos gobiernos, que han centrado casi exclusivamente su política en la necesidad vital de luchar contra el terrorismo. ${ }^{6}$

Si es necesario sistematizar las distintas situaciones conflictivas que han hecho estragos en el continente americano, se podría empezar por diferenciar los conflictos armados de los desórdenes o disturbios internos. Aunque la línea teórica de separación entre ambas se apoya en el grado de intensidad de la violencia, debe reconocerse que, en ocasiones, es muy difícil trazarla con precisión (A). La historia del continente también demuestra que la violencia no es privativa de ese tipo de manifestaciones. El terrorismo de Estado ha marcado las horas más sombrías de las dictaduras del "Cono Sur" en los años setenta y, en los ochenta, de los regímenes autoritarios de

6 Si el caso del gobierno Bush ha sido un ejemplo de ese proceso de instrumentalización (ver nota 5), el mismo tipo de consideraciones sirve con respecto al conflicto colombiano y al rechazo por parte del gobierno del presidente Uribe a reconocer los grupos armados llamados "rebeldes", ver Nieto, R. ¿Hay o no hay conflicto armado en Colombia? Anuario Colombiano de Derecho Internacional, Año 1, No 1, 2008, pp. 139-159. 
América Central. La especificidad del terrorismo de Estado es tal que su estudio requiere un apartado separado (B).

\section{A) Los conflictos armados frente a los disturbios internos}

Las situaciones que pueden ser calificadas como de conflicto armado han sido analizadas por los órganos del sistema interamericano bajo la perspectiva clásica del conjunto de reglas de Derecho Internacional que les son aplicables. Por ello se ha hecho, de forma lógica, una distinción entre la noción de conflicto armado (interno o internacional) y los simples "disturbios y tensiones internas", siguiendo lo establecido por el derecho internacional humanitario tal y como ha sido indicado por el Comité Internacional de la Cruz Roja (CICR). La Comisión Interamericana ha puesto de manifiesto de forma expresa las diferencias existentes entre las dos situaciones y ha subrayado la importancia de la diferenciación.

La Corte tuvo ocasión -dentro del marco de su función consultiva primero ${ }^{7}$ y contenciosa a continuación $-{ }^{8}$ de trazar las grandes líneas del régimen jurídico de los estados de excepción. ${ }^{9}$ Sin embargo, no se ha enfrentado aún a la compleja tarea de calificar ella misma la naturaleza de los hechos para determinar si se trata de "simples" disturbios internos (que quedan, pues, fuera del campo de la aplicación del derecho humanitario) o si, por el contrario, está ante un conflicto armado de violencia más radical (que entra en el ámbito de aplicación del ius in bello).

En la medida en que la propia Comisión Interamericana es la destinataria primera de las peticiones o comunicaciones, es ella, en realidad, la que asume la delicada labor de trazar una línea estable y segura entre lo que tiene suficiente gravedad y el resto. La Comisión afirmó así desde los primeros momentos de su actividad que determinar con precisión la naturaleza de un conflicto solo es posible mediante "un estudio objetivo de los hechos caso

7 Corte IDH, 30 de enero de 1987, El hábeas corpus en periodo de suspensión de garantías. Serie A, № 8; Corte IDH, opinión consultiva del 6 de octubre de 1987, Las garantías judiciales en periodo de estado de urgencia. Serie $\mathrm{A}, \mathrm{N}^{\circ} 9$.

8 Corte IDH, 30 de mayo de 1999, Fondo y reparaciones, Castillo Petruzzi c. Perú. Serie C, No 52, pár. 109; Corte IDH, 8 de julio del 2004, Fondo y reparaciones, Los hermanos Gómez Paquiyauri c. Perú. Serie C, No 110, pár. 85; Corte IDH, 4 de julio del 2007, Fondo y reparaciones, Zambrano Vélez c. Ecuador. Serie C, No 165, párs. 42-71.

9 El régimen jurídico aplicable a los estados de excepción será analizado en el marco de la segunda parte de este artículo. 
por caso". ${ }^{10}$ Los órganos interamericanos siguen el tenor de los principios creados por el CICR, que recientemente ha tenido la ocasión de recordar que es la situación de hecho la que debe ser tenida en cuenta para determinar la naturaleza de un conflicto y no el reconocimiento y, por lo tanto, la "calificación" de la situación hecha por las partes que intervienen en él. ${ }^{11}$

Lo dicho es particularmente importante en el caso de Colombia, donde el gobierno actual se ha lanzado a una "guerra de palabras" sintomática de la instrumentalización política del terror. El presidente Álvaro Uribe negó, con ocasión de una audiencia ante la Corte Interamericana, el reconocimiento de un estatus de cualquier tipo a la guerrilla y a los paramilitares, que, según él mismo manifiesta, son "terroristas" y de ninguna manera deben ser considerados como "combatientes". ${ }^{12}$ La Corte Interamericana no ha tomado, evidentemente, en consideración este discurso político, puesto que ella misma se esfuerza, sistemáticamente, en enmarcar los ataques a los derechos humanos dentro de su contexto histórico antes de proceder a la calificación jurídica del conflicto.

Dentro de la actividad contenciosa relativa a Colombia, ${ }^{13}$ la Corte ha llegado muy lejos en su categorización y en la evaluación jurídica de la

10 Comisión IDH, 18 de noviembre de 1997, Abella (asunto llamado "La Tablada") c. Argentina, asunto $\mathrm{N}^{\mathrm{0}} 11.137$, informe $\mathrm{N}^{\circ}$ 55/97, párs. 152 y 153.

11 Es necesario señalar que el CICR ha precisado, en una opinión publicada en marzo del 2008, la definición de "conflicto armado" según el derecho humanitario internacional. El Comité destaca, por un lado, la existencia de dos categorías jurídicas de "conflicto armado" (interno y no internacional) aportando en cada caso los textos, la jurisprudencia y la doctrina, mientras insiste, por otra parte, acerca de la importancia de los hechos y de su configuración, descartando de esta el "reconocimiento de la situación" por los que intervienen en ella, CICR, ¿Cuál es la definición de "conflicto armado" según el derecho internacional bumanitario? Dictamen de marzo del 2008; Fleck, D. The handbook of humanitarian law in armed conflict. Oxford: Oxford University Press, 1995, p. 45.

12 Declaraciones del presidente Uribe hechas el 19 de junio del 2003 ante la Corte Interamericana de Derechos Humanos: "No reconozco a los grupos violentos de Colombia, ni a la guerrilla ni a los paramilitares, la condición de combatientes; mi gobierno los señala como terroristas", reproducidas en Nieto, R. ¿Hay o no hay conflicto armado en Colombia?, op. cit., p. 140.

13 El "contencioso colombiano", ligado de manera casi sistemática al conflicto armado interno al que se enfrenta el país desde hace cuarenta años, es uno de los que más casos ha generado ante los órganos interamericanos, después de Perú (veintitrés casos) y Guatemala (doce casos). Hasta el 5 de abril del 2009, se cuentan diez casos importantes contra Colombia (y no diez sentencias, ya que un asunto ha dado lugar, a veces, a sentencias separadas sobre las excepciones preliminares, el fondo y las reparaciones). Ver, en orden cronológico, Corte 
actuación de las partes intervinientes en el conflicto (guerrilla, fuerzas armadas gubernamentales y paramilitares) y ha dedicado de manera explícita en todos los asuntos - a partir del caso relativo a la Masacre de Mapiripán- una parte específica titulada El conflicto armado interno en Colombia y los grupos armados ilegales denominados "paramilitares". ${ }^{14}$

Tras un análisis histórico en el que la Corte sitúa los orígenes del conflicto en el comienzo de los años sesenta con la aparición de grupos armados guerrilleros, la actitud del Estado en ese momento es puesta de relieve. Los jueces de San José señalan sin tapujos los orígenes de los famosos "grupos de autodefensa", señalando que fue el propio Estado, ni más ni menos, el que promovió su creación al reclutar y armar civiles, esgrimiendo como objetivo la necesidad de protegerse de los crímenes perpetrados por la guerrilla.

Lo que debía suceder sucedió, ya que no se pueden delegar, sin quedar impune, prerrogativas en grupos privados. Esas estructuras se transformaron a mediados de los años ochenta y terminaron por escapar del control del Estado. Y la Corte ha recordado que se convirtieron en "grupos delictivos" comúnmente llamados "paramilitares". ${ }^{15}$ Estando fuera de la ley, estos grupos perpetraron numerosas violaciones de los derechos humanos y, como si la situación no fuese ya lo suficientemente compleja, actuaron en algunos casos en connivencia con las fuerzas armadas gubernamentales.

IDH, 8 de diciembre de 1995, Fondo, Caballero Delgado y Santana c. Colombia. Serie C n ${ }^{a} 22$; Corte IDH, 6 de diciembre del 2001, Fondo, Las Palmeras c. Colombia. Serie C, $\mathrm{n}^{\mathrm{a}}$ 90; Corte IDH, 5 de julio del 2004, Fondo y reparaciones, Diecinueve comerciantes c. Colombia. Serie C, $\mathrm{n}^{\mathrm{a}}$ 109; Corte IDH, 12 de septiembre del 2005, Fondo, "Masacre de Mapiripán" c. Colombia. Serie C, $\mathrm{N}^{\circ}$ 134; Corte IDH, 31 de enero del 2006, Fondo y reparaciones, Matanza de Pueblo Bello c. Colombia. Serie C, No 140; Corte IDH, $1^{\circ}$ de julio del 2006, Excepciones preliminares, fondo y reparaciones, Masacre de Ituango c. Colombia. Serie C, No 148; Corte IDH, 11 de mayo del 2007, Fondo y reparaciones, Masacre de la Rochela c. Colombia. Serie C, No 163; Corte IDH, 4 de julio del 2007, Fondo y reparaciones, Escué Zapata c. Colombia. Serie C, No 165; Corte IDH, 27 de noviembre del 2008, Fondo y reparaciones, Valle Jaramillo y otros c. Colombia. Serie C, No 192.

14 Corte IDH, 15 de septiembre del 2005, Fondo y reparaciones, "Masacre de Mapiripán" c. Colombia. Serie C, No 134, párs. 96.1-96.2; Corte IDH, 31 de enero del 2006, Fondo y reparaciones, Masacre de Pueblo Bello c. Colombia. Serie C, No 140, párs. 95.1-95.20; Corte IDH, $1^{\circ}$ de julio del 2006, Excepciones preliminares, fondo y reparaciones, Masacres de Ituango c. Colombia. Serie C, $\mathrm{N}^{\circ} 148$, pár. 125.2.

15 Corte IDH, 15 de septiembre del 2005, Fondo y reparaciones, "Masacre de Mapiripán" c. Colombia. Serie C, No 134, pár. 96.3; Corte IDH, 31 de enero del 2006, Fondo y reparaciones, Masacre de Pueblo Bello c. Colombia. Serie C, No 140, pár. 95.3; Corte IDH, $1^{\circ}$ de julio del 2006, Excepciones preliminares, fondo y reparaciones, Masacres de Ituango c. Colombia. Serie C, $\mathrm{N}^{\circ}$ 148, pár. 125.2. 
El caso Valle Jaramilllo es muestra de ese entendimiento macabro y funesto entre los paramilitares y el Ejército Nacional, que se unieron in casu para asesinar a Jesús María Valle Jaramillo: abogado militante a favor de los derechos humanos, quien no había dejado de denunciar desde 1996 las extorsiones de los paramilitares, así como sus lazos con el Ejército Nacional. ${ }^{16}$ Aunque el gobierno colombiano reconoció su responsabilidad por no haber protegido de la manera debida la vida del Sr. Valle Jaramillo y no haber actuado para que se buscase, detuviese y juzgase a los responsables, rechazó que hubiese existido cualquier clase de acuerdo entre el Ejército y los paramilitares, así como una situación de persecución promovida por el Estado respecto a los defensores de los derechos humanos. ${ }^{17}$

Esta táctica judicial utilizada con regularidad por el Gobierno de Bogotá -rechazando el prisma analítico del contexto político- ${ }^{18}$ no ha sido aceptada por la jurisdicción de San José. La transcripción de los hechos históricos en los casos de violaciones graves de los derechos humanos ha permitido a la Corte delimitar los contornos de la responsabilidad del Estado, ${ }^{19}$ en particular en los supuestos en los que las violaciones se cometen por terceros. ${ }^{20}$ La movilización de la obligación del respeto y garantía de los derechos contenida en los artículos 1.1 y 2 de la Convención Americana sobre

16 Corte IDH, 27 de noviembre del 2008, Fondo y reparaciones, Valle Jaramillo y otros $c$. Colombia. Serie C, No 192, pár. 73.

17 Ibíd., pár. 20d).

18 Ad. ex., Corte IDH, 11 de mayo del 2007, Fondo y reparaciones, Masacre de la Rochela c. Colombia. Serie C, No 163, párs. 10-11.

19 Como ejemplos recientes en los que la Corte "contextualiza" las violaciones masivas de los derechos humanos perpetradas por los agentes del Estado, nos referiremos a dos asuntos relativos a desapariciones forzadas en contextos autoritarios. Así, el caso del golpe de Estado en Bolivia en 1980 y la instauración de la dictadura del general Luis García Meza (Corte IDH, 27 de noviembre del 2008, Fondo y reparaciones, Ticona Estrada y otros c. Bolivia. Serie C, N ${ }^{\circ}$ 191, párs. 45-49) y el conflicto armado interno en Guatemala entre 1962 y 1996, que dio lugar a más de doscientas mil ejecuciones sumarias y desapariciones forzadas (Corte IDH, 26 de noviembre del 2008, Fondo y reparaciones, Tiu Tojín c. Guatemala. Serie C, No 190, párs. 48-51).

20 Es un tema que la doctrina analiza con regularidad; ad. ex., Farrior, S. State responsability for human rights abuses by non State actors. American Society of International Law Proceedings, (92), 1998, p. 299; Pinto, M. Responsabilidad internacional por la violación de los derechos humanos y los entes no estatales. Héctor Gros Espiell Amicorum Liber. Bruxelles: Bruylant, 1997, pp. $1155-1173$. 
Derechos Humanos -obligaciones erga omnes ${ }^{21}$ proporciona los medios a la Corte Interamericana para que los Estados se enfrenten a sus responsabilidades y para sancionarlos por incumplir sus obligaciones. ${ }^{22}$

La estrategia consistente en negar todo lazo con los grupos privados no funciona gracias a los resortes del establecimiento de las obligaciones de prevención y de protección. Aunque la Corte ha enunciado los límites de la imputabilidad al Estado de los actos de personas o de grupos privados, no ha tenido realmente la ocasión, hasta ahora, de activarlos en beneficio de los Estados. ${ }^{23}$

Una vez más, la Corte Interamericana se aproxima a la jurisprudencia del Tribunal Europeo de derechos humanos - ¿o es, más bien, al revés?-y traza el marco de las condiciones de la responsabilidad estatal. ${ }^{24}$ Pero no se detiene ahí, sino que va todavía más lejos. Aunque, en efecto, comprueba regularmente (sobre todo en los asuntos colombianos) que el Estado ha reformado su legislación para prevenir y castigar las actividades de los paramilitares, también ha constatado que esas medidas no han contribuido a desactivar de manera eficaz el riesgo que se ha creado.

Por eso, el Estado no solo es culpable de los errores del pasado - pese a sus intentos, en la actualidad, de resolver la situación conflictiva-, sino que, además, tiene una "responsabilidad agravada" por tales actuaciones. Creación jurisprudencial interamericana, la existencia de un riesgo real y objetivo

21 Para entender la construcción dogmática que se encuentra en la base de esta calificación, ver Burgorgue-Larsen, L. \& Úbeda de Torres, A. Les grandes décisions de la Cour interaméricaine des droits de l'homme. Bruxelles: Bruylant, 2008, spec. pp. 270-303 (commentaire No 11).

22 Corte IDH, 15 de septiembre del 2005, Fondo y reparaciones, Masacre de Mapiripán c. Colombia. Serie C, No 134, pár. 111: "La atribución de responsabilidad al Estado por actos de particulares puede darse en casos en que el Estado incumple, por acción u omisión de sus agentes cuando se encuentren en posición de garantes, esas obligaciones erga omnes contenidas en los artículos 1.1 y 2 de la Convención"; ver igualmente Corte IDH, 11 de mayo del 2007, Fondo y reparaciones, Masacre de la Rochela c. Colombia. Serie C, No 163, párs. 67-68.

23 Corte IDH, 31 de enero del 2006, Fondo y reparaciones, Masacre de Pueblo Bello c. Colombia. Serie C, No 140, pár. 123: "El carácter erga omnes de las obligaciones convencionales de garantía a cargo de los Estados no implica una responsabilidad ilimitada de los Estados frente a cualquier acto o hecho de particulares, pues sus deberes de adoptar medidas de prevención y protección de los particulares en sus relaciones entre sí se encuentran condicionados al conocimiento de una situación de riesgo real e inmediato para un individuo o grupo de individuos determinado y a las posibilidades razonables de prevenir o evitar ese riesgo". (La negrita es de las autoras).

24 TEDH, 28 de marzo del 2000, Kiliç c. Turquía, párs. 62-63; TEDH, 28 de octubre de 1998, Osman c. Reino Unido, párs. 115-116. 
derivado de la participación de los paramilitares en el conflicto colombiano acentúa los deberes especiales de prevención y de protección que pesan sobre el Estado en las regiones donde los paramilitares están presentes.

La Corte recordaba de manera solemne este elemento en particular en consideración a los defensores de los derechos humanos, ${ }^{25}$ cuya vulnerabilidad ha sido puesta de relieve. Utilizada como criterio interpretativo de peso para imponer obligaciones reforzadas, ${ }^{26}$ la vulnerabilidad es con toda certeza uno de los criterios clave del juez interamericano, que no teme poner en marcha mecanismos cuya filosofía se basa en la discriminación positiva para imponer a los Estados políticas de lucha contra las desigualdades llamativas y estructurales. ${ }^{27}$

\section{B) El terrorismo de Estado}

Eliminar el terrorismo de Estado de este análisis no hubiera permitido dar cuenta de las múltiples facetas de la(s) guerra(s) "sucias" que castigaron al continente en la época de las dictaduras. Los mandatos del argentino Jorge Videla, ${ }^{28}$ del boliviano Hugo Banzer, ${ }^{29}$ de los brasileños Humberto Castello

25 Corte IDH, 27 de noviembre del 2008, Fondo y reparaciones, Valle Jaramillo y otros $c$. Colombia. Serie C, $\mathrm{N}^{\circ} 192$, pár. 80.

26 Los niños (Corte IDH, 19 de noviembre de 1999, Fondo, Villagrán Morales y otros c. Guatemala. Serie C, No 63), las mujeres (Corte IDH, 25 de noviembre del 2006, Fondo y reparaciones, Prison Miguel Castro Castro c. Perú. Serie C, No 160), los enfermos (Corte IDH, 4 de julio del 2006, Fondo y reparaciones, Ximenes Lopes c. Brasil. Serie C, No 149), pero también los detenidos (Corte IDH, 7 de septiembre del 2004, Tibi c. Ecuador. Serie C, No 114), los trabajadores inmigrantes (Corte IDH, 17 de septiembre del 2003, Estatuto jurídico y derechos de los trabajadores migrantes indocumentados. Serie A, $\mathrm{N}^{\circ} 18$ ), los desplazados (Corte IDH, $1^{\circ}$ de julio del 2006, Fondo y reparaciones, Masacre de Ituango c. Colombia. Serie C, $\mathrm{N}^{\circ}$ 48) o incluso los pueblos indígenas (Corte IDH, 31 de agosto del 2001, Fondo y reparaciones, Comunidad Mayagna (Sumo) Awas Tigni c. Nicaragua. Serie C, $\mathrm{N}^{\circ} 79$ ), son personas y grupos vulnerables que la Corte ha identificado como tales y con respecto a los cuales impone a los Estados deberes especiales de protección.

27 Acerca de la no discriminación y de sus corolarios, nos remitimos a Burgorgue-Larsen, L. Le principe et d'égalité et de non-discrimination dans la jurisprudence interaméricaine des droits de l'homme. In: Sudre, F. \& Surrel, H. (dirs.). Le droit à la non-discrimination au sens de la Convention européenne des droits de l'bomme. Bruxelles: Bruylant, 2008, pp. 242-247, 266-268, 282-287, 291-293, 309, 319-323.

28 Entre 1976 y 1983.

29 Entre 1971 y 1978. 
Branco $^{30}$ y Arthur da Costa e Silva, ${ }^{31}$ la del chileno Augusto Pinochet, ${ }^{32}$ del paraguayo Alfredo Stroessner y la del uruguayo Juan María Borderry ${ }^{33}$ han sido el origen de un terror transfronterizo que se llamó en clave "Operación Cóndor", nombre que recibió la "alianza de las fuerzas de seguridad y de los servicios de inteligencia de las dictaduras del Cono Sur". ${ }^{34}$

Todos ellos fueron los funestos artífices de acciones en las que el terrorismo de Estado llegó al paroxismo. No faltan las obras artísticas, en particular las cinematográficas, ${ }^{35}$ así como los trabajos de investigación acerca de ese período, tanto históricos ${ }^{36}$ y literarios ${ }^{37} \operatorname{como}_{\text {jurídicos, estos últimos }}$ numerosísimos. ${ }^{38}$ Dichos trabajos son excepcionales cuando utilizan las herramientas de la sociología para desentrañar los engranajes de las violaciones masivas de los derechos humanos.

Es importante, a este respecto, la publicación de la obra del profesor americano Mark Oisel, que permite destapar las dificultades de la justicia transicional en el marco de la creación de una memoria colectiva de las naciones y de los pueblos. ${ }^{39}$ Este terror no solo fue desenmascarado, sino también "condenado" por la Corte de San José en casos considerados como

30 Entre 1964 y 1967.

31 Entre 1964 y 1967.

32 Entre 1973 y 1980.

33 Entre 1973 y 1976.

34 Corte IDH, 26 de septiembre del 2006, Fondo y reparaciones, Almonacid Arellano y otros c. Chile. Serie C, No 154, pár. 64.

35 Como la película Missing, dirigida por Costa-Gavras y que obtuvo la Palma de Oro en Cannes en 1982, así como el Premio al Mejor Actor para Jack Lemmon. El film describe el terror sordo que reinó entre Viña del Mar y Santiago los primeros días que siguieron al 11 de septiembre de 1973.

36 Dinges, J. Les Années Condor. Comment Pinochet et ses alliés ont propagé le terrorisme sur trois continents. Paris: La Découverte, 2005.

37 Melo, A. \& Raffin, M. Obsesiones y fantasmas de la Argentina. El antisemitismo, Evita, los desaparecidos y Malvinas en la ficción literaria. Buenos Aires: Ediciones del Puerto, 2005, 221 p.

38 Ad. ex., Pinto, M. L'Amérique latine et le traitement des violations massives des droits de l'homme. Paris: Pedone, 2007, 96 p., Col. Institut des Hautes Etudes Internationales, Cours et Travaux $\mathrm{N}^{\circ} 7$.

39 Oisel, M. Juger les crimes de masse. La mémoire collective et le droit. Paris: Seuil, 2006, 453 p. Préface d'A. Garapon. 
históricos. Las sentencias Almonacid Arellano ${ }^{40}$ y Goibur $u^{41}$ ponen al descubierto ante la justicia el terror transfronterizo ${ }^{42}$ y la subsiguiente responsabilidad de los Estados por haber orquestado la perpetración de crímenes contra la humanidad, cuya imprescriptibilidad ${ }^{43}$ ha sido proclamada por la Corte y la jurisprudencia internacional al unísono.

El caso Goiburú brindó igualmente la ocasión para que la Corte, convirtiéndose nuevamente en pionera, afirmase que la prohibición de las desapariciones forzadas y el deber correlativo de buscar a las víctimas y de sancionar a los responsables se ha convertido en ius cogens. ${ }^{44}$ Tras haber inventado, gracias a los resortes de una visión imaginativa puesta al servicio de la lucha contra la impunidad, la teoría de la presunción de la muerte en la célebre sentencia Velásquez, Rodríguez, ${ }_{3}^{45}$ la Corte rizó el rizo consagrando el acceso a la justicia, en materia de desapariciones forzadas, como una norma de ius cogens.

40 Corte IDH, 26 de septiembre del 2006, Fondo y reparaciones, Almonacid Arellano y otros c. Chile. Serie $\mathrm{C}, \mathrm{N}^{\circ} 154$.

41 Corte IDH, 22 de septiembre del 2006, Fondo y reparaciones, Goiburú c. Paraguay. Serie C, $\mathrm{N}^{\circ} 153$.

42 Ibíd., pár. 62. Tal y como establece la Corte, los crímenes tuvieron lugar dentro de un contexto marcado por la práctica sistemática de detenciones arbitrarias, torturas, ejecuciones y desapariciones perpetradas por las fuerzas de seguridad e inteligencia de la dictadura de Alfredo Stroessner en el marco de la Operación Cóndor. Su gravedad se pone de manifiesto por el carácter flagrante, masivo y sistemático de la represión a escala interestatal a la que se sometió a la población, en la medida en la que los gobiernos dictatoriales pusieron en marcha una coordinación transfronteriza de las estructuras de seguridad. Estos casos muestran claramente la existencia de un orden internacional de los derechos humanos en el que se entretejen decisiones y análisis de órganos distintos. En efecto, el Comité de Derechos Humanos de las Naciones Unidas ha tenido también ocasión de interesarse por el terrorismo de Estado y por la práctica de detención y tortura transfronteriza. Ver, por ejemplo, el célebre asunto López Burgos c. Uruguay, en el que se condena al Estado uruguayo por hechos sucedidos en Argentina con la colaboración de la Policía y del Ejército argentino, comm. No R.12/52, Sergio Rubén López Burgos c. Uruguay, A/36/40, p. 189.

43 Corte IDH, 26 de septiembre del 2006, Fondo y reparaciones, Almonacid Arellano y otros c. Chile. Serie C, No 154, párs. 105-114.

44 Corte IDH, 22 de septiembre del 2006, Fondo y reparaciones, Goiburú c. Paraguay. Serie C, $N^{\circ} 153$, párs. 84 y 93, así como 128 y 131. La Corte ha confirmado este dictum en varias ocasiones, ver Corte IDH, 29 de noviembre del 2006, Fondo y reparaciones, La Cantuta c. Perú. Serie C, No 162, pár. 157; Corte IDH, 26 de noviembre del 2008, Fondo y reparaciones, Tiu Tojin c. Guatemala. Serie C, No 190, pár. 91.

45 Grossman, C. The Velásquez Rodríguez Case: the development of the Inter-American Human Rights System. International Law Stories, Foundation Press, 2007, pp. 77-113. 
Aunque hoy en día la "fisonomía" del contencioso interamericano se halla en proceso de transformación, tratando paulatinamente de problemas más "clásicos" propios de sociedades democráticas, ${ }^{46}$ la Corte tendrá todavía que conocer de asuntos relativos a estas "guerras" proteiformes. Primero, porque a algunos países les cuesta volver la página y dejar atrás sus viejos demonios. En segundo lugar y sobre todo, porque supondría borrar demasiado fácilmente el peso del tiempo. Es necesario, a menudo, mucho tiempo antes de que un asunto presentado ante la Comisión por las organizaciones no gubernamentales $(\mathrm{ONG})$ y/o las víctimas o sus allegados -a veces mucho después de producidos los hechos-acabe por llegar ante la Corte Interamericana. ${ }^{47}$ En este contexto, la determinación de la existencia de una responsa-

46 La diversificación del contencioso interamericano es un hecho probado desde hace ya varios años: así, se han desarrollado casos relativos al derecho a la nacionalidad (Corte IDH, 8 de septiembre del 2005, Fondo y reparaciones, Las niñas Yean y Bosico c. República Dominicana. Serie $\mathrm{C}, \mathrm{N}^{\circ} 130$ ), el derecho de propiedad (Corte IDH, 31 de agosto del 2001, Fondo y reparaciones, Comunidad Mayagna (Sumo) Awas Tigni c. Nicaragua. Serie C, No 79; Corte IDH, 6 de mayo del 2008, Excepciones preliminares y Fondo, Salvador Chiriboga c. Ecuador, Serie C, N ${ }^{\circ} 179$ ), los derechos políticos (Corte IDH, 23 de junio del 2005, Fondo y reparaciones, Yatama c. Nicaragua. Serie C, No 127; Corte IDH, 6 de agosto del 2008, Excepciones preliminares, Fondo y reparaciones, Castañeda Gutman c. México. Serie C, No 184), el derecho de los enfermos (Corte IDH, 4 de julio del 2006, Fondo y reparaciones, Ximenes Lopes c. Brasil. Serie $C, \mathrm{~N}^{\circ} 149$ ) o incluso los asuntos relativos a la libertad de expresión (ad. ex., Corte IDH, 6 de febrero del 2001, Ivcher Bronstein c. Perú. Serie C, No 74; Corte IDH, 22 de noviembre del 2005, Fondo y reparaciones, Palamara Iribarne c. Chile. Serie C, No 135; Corte IDH, 19 de septiembre del 2006, Fondo y reparaciones, Claude Reyes c. Chile. Serie C, No 151; Corte IDH, 2 de mayo del 2008, Fondo y reparaciones, Kimel c. Argentina. Serie C, No 177; Corte IDH, 27 de enero del 2009, Fondo y reparaciones, Tristán Donoso c. Panamá. Serie C, No 193). Todos ellos son cuestiones que han entrado paulatinamente en el universo judicial interamericano, ver Burgorgue-Larsen, L. Les nouvelles tendances de la jurisprudence interaméricaine des droits de l'homme. Cursos de Derecho Internacional y Relaciones Internacionales de Vitoria-Gasteiz 2008. Bilbao, 2009, en prensa.

47 Señalemos un asunto reciente, que pone de manifiesto que en ocasiones puede transcurrir mucho tiempo antes de que la Corte resuelva sobre los hechos que dieron lugar a violaciones graves de derechos humanos (Corte IDH, 12 de agosto del 2008, Excepciones preliminares, Fondo y reparaciones, Heliodoro Portugal c. Panamá. Serie C, No 186). La víctima, el señor Heliodoro Portugal, desapareció el 14 de mayo de 1970 en plena dictadura militar. Su hija no pudo interponer una acción judicial hasta comienzos de los años noventa, en el momento en el que la democracia volvía al país. La Comisión Interamericana fue contactada a través del Centro por la Justicia y el Derecho Internacional (CEJIL), así como por la hija de la víctima (Patria Portugal) el 2 de junio del 2001. Tras examinar el asunto, la Comisión lo sometió, a su vez, a la Corte, el 23 de enero del 2007. Panamá fue condenada el 12 de agosto del 2008, es decir, cuarenta y ocho años después de los hechos, por violación de varias disposiciones de 
bilidad agravada para hacer frente a los asesinatos, desapariciones, torturas y detenciones transfronterizas que acompañan al "terrorismo de Estado" es capital para la Corte, que trata, a su manera, tanto de evitar la repetición de tales fenómenos como de luchar contra la impunidad.

Si la Corte ha puesto de relieve la particular responsabilidad y las "obligaciones especiales" del Estado en el marco de los asuntos en los que las violaciones de la Convención provenían de grupos privados, no ha podido sino reiterar esta apreciación en los casos en los que las violaciones masivas han sido perpetradas directamente por los agentes del Estado. La Corte ha condenado, pues, "la instrumentalización del poder estatal en tanto que medio y recurso para cometer violaciones de los derechos que hubieran debido ser respetados y garantizados (...). El Estado se ha convertido en el elemento principal de la perpetración de crímenes tan graves que corresponden, claramente, a una situación de "terrorismo de Estado". ${ }^{48}$

La responsabilidad del Estado se "agrava” cuando las desapariciones forzadas, las torturas y las detenciones forman parte de un patrón sistemático de violaciones toleradas o cometidas por el Estado en el marco de una situación general de impunidad. Aunque esta noción ha suscitado la crítica en el seno de la propia Corte, ${ }^{49}$ no es menos cierto que impregna hoy toda la jurisprudencia interamericana; una construcción jurisprudencial que, sin duda, debe mucho a la teoría del "crimen internacional" construida en otros tiempos por la Comisión de Derecho Internacional, en el célebre artículo 19 del proyecto relativo a la responsabilidad del Estado. ${ }^{50}$

la Convención Americana, así como de las convenciones interamericanas contra las desapariciones forzadas y contra la tortura, declarando al Estado culpable tanto por lo sucedido a la víctima como por el sufrimiento de sus allegados (ver párrafos 4-8 de los puntos resolutivos). 48 Corte IDH, 22 de septiembre del 2006, Fondo y reparaciones, Goiburú c. Paraguay. Serie C, $\mathrm{N}^{\circ} 153$, pár. 66.

49 El ex presidente de la Corte, Sergio García Ramírez, afirma, sin embargo, sus reservas en lo referente a la utilización de la fórmula de "responsabilidad agravada". A su juicio, la responsabilidad no puede agravarse o atenuarse, ya que la responsabilidad supone solamente, sin consideraciones acerca de la intensidad, la posibilidad o la necesidad de ser deudor de ciertos hechos en virtud de un título jurídico de imputabilidad que liga la conducta a una determinada persona, la cual debe responder por esa conducta a través del establecimiento de ciertas consecuencias jurídicas, ver la opinión separada del juez García Ramírez a la sentencia Goiburú, pár. 3.

50 Ver a este respecto la opinión separada del juez A. Cançado Trindade (párs. 41 y ss.) a la sentencia Corte IDH, 23 de noviembre del 2003, Fondo y reparaciones, Myrna Mack Chang c. Guatemala. Serie C, No 101. 


\section{El derecho aplicable a los conflictos}

La importancia de la necesidad de distinguir entre la noción de conflicto armado y los simples "disturbios y tensiones internas" se debe a la determinación del derecho aplicable a los diferentes tipos de situaciones. La Comisión Interamericana, siguiendo la evolución del Derecho Internacional actual, ${ }^{51}$ ha constatado de forma expresa las diferencias de régimen aplicables a las dos situaciones y subrayado la importancia de la diferenciación. Ha concluido así que "los motines, los actos de violencia esporádicos y las rebeliones no organizadas" -si son de corta duración y no revisten gravedad- están excluidos, en principio, de la protección del derecho de la guerra, según lo establecido por el artículo 1.2 del Protocolo Adicional II a las Convenciones de Ginebra. ${ }^{52}$

Pero si el derecho de la guerra no se aplica a las situaciones de crisis internas, el derecho de los derechos humanos, por el contrario, sí que encuentra su lugar. La declaración del estado de excepción por parte de un Estado no equivale a la exclusión integral de las reglas que rigen el funcionamiento de los Estados de derecho. No dota al Estado de poderes arbitrarios; el recurso al estado de urgencia tampoco suprime todas las obligaciones estatales que se derivan de los textos de protección de los derechos, empezando por la propia Convención Americana.

$\mathrm{Al}$ abordar la cuestión del derecho aplicable a los conflictos armados, aparece, de nuevo, el eterno problema de la interconexión entre dos grandes ramas del Derecho Internacional (los derechos humanos y el Derecho Internacional Humanitario). ${ }^{53}$ Con la proliferación de jurisdicciones

51 Se puede encontrar una excelente síntesis de todos los desarrollos normativos y jurisprudenciales que se refieren al ius in bello en Momtaz, D. Les règles et les institutions du Droit International Humanitaire à l'épreuve des conflits armés récents. Leiden-Boston: Centre d'étude et de recherche de droit international et de relations internationales 2007, Martinus Nijhoff Publishers, 2008, 227 p.

52 En efecto, esta disposición excluye de su campo de aplicación las situaciones de tensiones y de disturbios internos como los motines, los actos aislados y esporádicos de violencia y otros semejantes. Otros instrumentos internacionales han excluido en términos similares tales situaciones de su campo de aplicación, así el artículo 2f) del Estatuto de Roma, que crea la Corte Penal Internacional (CPI) y el artículo 22.2 del segundo protocolo relativo a la Convención de La Haya de 1954 para la protección de los bienes culturales en caso de conflicto armado, que excluye en los mismos términos de su campo de aplicación los disturbios y tensiones internas.

53 No es preciso remontarse mucho en el tiempo para darse cuenta de que la doctrina, ya en 
internacionales, ${ }^{54}$ este tema ha tomado un giro menos teórico estos últimos años, ya que, en el marco de su cometido, dichas jurisdicciones se han debido pronunciar, directa o indirectamente, sobre estas cuestiones.

Desde los tribunales penales internacionales, pasando por los de protección de los derechos humanos, este problema ha sido tratado (juna vez más! ${ }^{55}$ por los jueces. Hay que reconocer, sin embargo, que si el debate se relanzó con fuerza hace unos años, fue en parte por la posición tomada por la jurisdicción universal. Así, en el dictamen consultivo sobre la licitud de la amenaza o del empleo de armas nucleares, el Tribunal Internacional de Justicia consideró que la protección ofrecida por el Pacto Internacional de Derechos Civiles y Políticos no se interrumpe en tiempo de guerra, salvo en virtud del artículo $4^{\circ}$ del Pacto, que prevé que pueden ser derogadas, en caso de peligro público, algunas de las obligaciones que impone ese instrumento.

A nadie se le puede privar de su vida de forma arbitraria, pero la definición de lo que se considera arbitrario corresponde, según el TIJ, "a la lex specialis aplicable, es decir, el derecho aplicable a los conflictos armados" ${ }^{56}$ La jurisdicción universal ha confirmado su postura en el dictamen sobre las consecuencias jurídicas de la construcción de un muro en el territorio palestino ocupado, poniendo de manifiesto que no es el derecho de los derechos humanos el que determina, en caso de un conflicto armado, el régimen del derecho a la vida, sino el derecho internacional humanitario.

En cualquier caso, matizaba su posición precisando que "[e]n las relaciones entre el derecho internacional humanitario y los derechos humanos,

los años setenta, se ocupaba de estas cuestiones, ad. ex., Meyrowitz, H. Le droit de la guerre et les droits de l'homme. RDP, 5, 1972, p. 1059; Suter, K. D. An inquiry into the meaning of the phrase of "human rights in armed conflicts". Revue de Droit Pénal Militaire et de Droit de la Guerre, 15(3-4), 1976, p. 393.

54 La juridictionnalisation du Droit International. Paris: Pedone, SFDI, 2003.

55 Uno de los mayores fenómenos estos últimos años se refiere al papel del juez, tanto en las sociedades nacionales como a escala internacional, así como en los sistemas de integración económica y los sistemas convencionales de protección de los derechos. Como ensayo sociológico, nos referiremos a Garapon, A. \& Allard, J. Les juges dans la mondialisation. La nouvelle révolution du droit. Paris: Editions du Seuil et La République des idées, 2005, 96 p. Los autores se refieren a un "diálogo de los jueces" constructivo. Acerca de las incursiones en el derecho interno, nos remitimos a los bellos análisis recogidos en Mélanges en l'bonneur du président Bruno Genevois. Le dialogue des juges. Paris : Dalloz, 2009, así como en Bribosia, E. ; Scheeck, L. \& Úbeda de Torres, A. (eds.). L'Europe des Cours. Bruxelles : Bruylant, en prensa.

56 TIJ, Dictamen de 8 de julio de 1996, La legalidad de la amenaza o el empleo de armas nucleares. Rec. CIJ 1996, p. 226, pár. 25. 
tres situaciones pueden, pues, presentarse: algunos derechos pueden proceder exclusivamente del derecho internacional humanitario; otros, exclusivamente de los derechos humanos y otros, por último, pueden proceder, a la vez, de esas dos ramas del Derecho Internacional". ${ }^{57} \mathrm{El} \mathrm{TIJ} \mathrm{daba} \mathrm{así} \mathrm{un}$ paso más aun al abandonar (¿quizás provisionalmente?) esta división radical entre las dos ramas en la disputa que enfrentó Congo a Uganda. Toda referencia a la lex specialis desaparece aquí del lenguaje del Tribunal, que se limita a recordar que "estas dos ramas del Derecho Internacional, a saber, el derecho internacional de los derechos humanos y el derecho internacional humanitario, debían ser tenidas en consideración". ${ }^{58}$

Las afirmaciones realizadas por el Tribunal Internacional de Justicia han dado lugar a numerosos trabajos doctrinales de envergadura, y algunos autores aprovecharon la ocasión para poner de manifiesto el hecho de que, tanto la Comisión como la Corte Interamericanas, habían, desde hacía mucho tiempo, estado enfrentadas respecto de los lazos (complejos) entre los derechos humanos y el derecho internacional humanitario. ${ }^{59}$

Si el derecho de los conflictos armados (A) se halla en el corazón de la polémica, el derecho de los regímenes de excepción no debe quedar en el olvido. La Corte Interamericana se ha esforzado en dibujar con exactitud los contornos de la "cláusula de excepción" del artículo 27 de la Convención Americana y del necesario respeto por parte de los Estados de los principios inherentes a toda sociedad democrática (B).

\section{A) E1 derecho de los conflictos armados}

El tema central que se ha planteado a la Comisión, primero, y a la Corte Interamericana, después, ha sido el de determinar qué derecho es aplicable

57 TIJ, Dictamen de 9 de julio del 2004, Consecuencias jurídicas de la construcción de un muro en el territorio palestino ocupado. Rec. CIJ 2004, p. 178, \$106.

58 TIJ, 19 de diciembre del 2005, sentencia sobre las actividades armadas en el territorio del Congo (República Democrática del Congo c. Uganda). Rec. CIJ 2005, pár. 216.

59 Ver, en este sentido, el número especial de la Revista Internacional de la Cruz Roja de septiembre del 2008 y, más concretamente, la muy enriquecedora contribución de Droege, C. Efective affinities? Human rights and humanitarian law. IRRC-RICR, September 2008, pp. 501-548; ver también el número especial de la European Human Rights Law Review del 2008, donde se puede encontrar una contribución centrada exclusivamente en el sistema interamericano; ver MacCarthy, C. Human Rights and the laws of war under the American Convention on Human Rights. European Human Rights Law Review, 6, 2008, pp. 762-778. 
a los conflictos armados, una cuestión que a priori no tiene vínculo directo con su cometido o sus normas de referencia. Si el derecho internacional humanitario en el sistema interamericano ha parecido, durante un tiempo, jugar un papel delicado -debido a las diferencias de puntos de vista entre los dos órganos del sistema-, la situación ha terminado por estabilizarse hasta el punto de que el sistema interamericano, en este aspecto concreto, parece adelantarse al sistema europeo una vez más.

El ius in bello no es el derecho que los jueces de los derechos humanos están obligados a aplicar; el sistema interamericano de protección no deroga esta regla. El artículo 62.3 de la Convención Americana define claramente los límites de la competencia rationae materiae ${ }^{60}$ de la Corte y no integra el derecho de los conflictos armados. Sin embargo, si la Corte de San José ha subrayado muy pronto que se otorgaba la posibilidad de recurrir a otros "tratados internacionales" distintos de la Convención Americana para la interpretación de esta, ${ }^{61}$ lo cual se ha convertido en una auténtica estrategia interpretativa, eso no implica que dichos tratados puedan ser aplicables a los casos que la Corte debe examinar.

Aunque interpretar no es aplicar de una manera formal, la Comisión Interamericana trató a pesar de todo de difuminar dicha distinción. El caso La Tablada ${ }^{62}$ se convirtió así en el centro de una disputatio de envergadura, sobre este punto, ${ }^{63}$ entre la Comisión y la Corte. El caso, muy célebre en el hemisferio sur, se refería al asalto de varios cuarteles militares argentinos por un grupo de personas armadas pertenecientes al movimiento Todos por la Patria. La confrontación armada, que duró cerca de treinta horas, se saldó con la muerte de veintinueve personas entre los atacantes y varios miembros de las Fuerzas Armadas.

60 Según la cual la Corte puede conocer de toda cuestión que se refiera a la interpretación y a la aplicación de las disposiciones de la $\mathrm{CADH}$, siempre que los Estados encausados hayan reconocido o reconozcan su competencia, ya sea a través de una declaración especial o por un acuerdo.

61 Corte IDH, opinión consultiva de 24 de septiembre de 1982, "Otros tratados" objeto de la función consultiva de la Corte (articulo 64 de la CADH). Serie A, No 1.

62 Zegveld, L. La Comisión Interamericana de Derechos Humanos y el derecho internacional humanitario: comentario acerca del caso "La Tablada". RICR, No 147, septiembre 1998, pp. 547-554.

63 Comisión IDH, 18 de noviembre de 1997, Abella (asunto llamado de "La Tablada") c. Argentina, asunto $\mathrm{N}^{\circ} 11.137$, Informe sobre el fondo $\mathrm{N}^{\circ} 55 / 97$. No fue la única; nos referiremos igualmente a Comisión IDH, 30 de septiembre de 1997, Arturo Ribón Ávila c. Colombia, asunto $\mathrm{N}^{\circ} 11.142$, Informe $\mathrm{N}^{\circ} 26 / 97$. 
Los supervivientes del ataque alegaron que los militares rechazaron su propuesta de rendición y, al final de los combates, ejecutaron de manera sumaria a cuatro personas e hicieron desaparecer a otras seis. En la fase de examen de la petición, la Comisión consideró que era competente para "aplicar directamente" el derecho internacional humanitario. Alegación por lo menos osada, por no decir provocativa. ${ }^{64} \mathrm{El}$ problema fue zanjado por la Corte, que dijo la última palabra en la sentencia Las Palmeras ${ }^{65}$ Los hechos de este caso tratan de una operación armada organizada de forma conjunta por las fuerzas de la Policía y el Ejército colombianos en la localidad de Las Palmeras, que provocó la muerte de seis personas.

Los responsables de la matanza trataron de quitarse su responsabilidad, explicando que la muerte de dichos civiles se había producido a causa del enfrentamiento entre elementos "subversivos"; se retocaron las pruebas e

64 Dio varios argumentos para justificar esa interpretación. Primero, alegó el carácter inadecuado de tratados como la Convención Americana de los Derechos Humanos para hacer frente a conflictos importantes. Segundo, consideraba que había un solapamiento entre el artículo $3^{\circ}$, común a los cuatro Convenios de Ginebra y la Convención Americana en el marco de los conflictos armados internos: tanto el derecho internacional humanitario como el artículo $4^{\circ}$ de la Convención Americana prohíben las ejecuciones sumarias. Sin embargo, la Convención Americana no contiene disposiciones que definan o diferencien a los civiles de los combatientes. Por consiguiente, "la Comisión debe necesariamente referirse y aplicar los estándares y las reglas pertinentes del derecho humanitario como fuentes de interpretación autorizadas (...)”, ya que, en caso contrario, su competencia podría verse reducida o ser inexistente (ibíd., pár. 161). Tercero, todos los Estados miembros de la OEA y los Estados que forman parte de la Convención han ratificado al menos uno de los Convenios de Ginebra. Estos Convenios son, pues, aplicables en su derecho interno y, según el artículo 25, la Comisión podrá conocer de cuestiones relativas a la ausencia de recurso efectivo respecto de los derechos "reconocidos por la Constitución, la Ley o la Convención" (ibíd., pár. 163; el subrayado es de la propia Comisión). Por último, la Comisión propuso la existencia de dos posibles bases jurídicas convencionales indirectas. Por un lado, el artículo 29b) -que exige aplicar el principio pro homine-, el cual podría, indirectamente, imponer a la Comisión la aplicación del derecho internacional humanitario, ya que esta norma "contiene el standard más elevado de protección” (ibíd., pár. 165); por otro, el artículo 27, que exige que se asegure la compatibilidad con "las otras obligaciones impuestas por el Derecho Internacional". La Comisión Interamericana dedujo que, en el momento de analizar las medidas de suspensión tomadas en el marco de un estado de excepción, se podría concluir que dichas medidas de suspensión violan las obligaciones de los Estados que son parte tanto de la Convención Americana como de los respectivos tratados de derecho humanitario (pár. 170).

65 Corte IDH, 4 de febrero del 2000, Excepciones preliminares, Las Palmeras c. Colombia. Serie C, No 67, y Corte IDH, 6 de diciembre del 2001, Fondo, Las Palmeras c. Colombia. Serie C, $N^{\circ} 90$; ver Martin, F. Application du Droit International Humanitaire par la Cour interaméricaine des droits de l’homme. RICR, 83(844), 2003, pp. 1037-1066. 
intimidaron a los testigos para que el asunto no trascendiera, pero fue inútil. Los procesos abiertos en su contra para la imposición de sanciones disciplinarias no llegaron a ninguna condena y los procedimientos penales abiertos en el ámbito militar solo se encontraban en fase de instrucción cuando la Comisión Interamericana (la demanda se presentó el 27 de enero de 1994) entregó su informe (cuatro años más tarde). ${ }^{66}$

La Corte se vio obligada, antes de resolver sobre el fondo del asunto, ${ }^{67}$ a examinar y resolver las cinco excepciones preliminares planteadas por el gobierno colombiano. Estas se referían, respectivamente, a la violación del proceso equitativo por parte de la Comisión Interamericana (primera excepción), a la incompetencia de la Corte y de la Comisión para aplicar el derecho internacional humanitario (tercera y segunda excepciones), al no agotamiento de las vías de recurso internas (cuarta excepción) y, por último, a la falta de competencia de la Corte para actuar como una jurisdicción de instrucción (quinta excepción).

La Corte admitió dos de las cinco excepciones preliminares y con esto estableció claramente los límites del Derecho que podía aplicar. La Corte respondió de manera clara y unívoca: la Convención Americana ha atribuido únicamente a la Corte la competencia para determinar la compatibilidad de los actos o de las normas de los Estados con la Convención y no con los Convenios de Ginebra de 1949 (par. 33). Dicho respeto del principio de las competencias de atribución por la Corte de San José ha sido criticado en razón de los lazos tan estrechos que unen a los derechos humanos y al derecho internacional humanitario, lazos que la Corte parece no haber querido ver y valorar. Si en el asunto Bámaca Velásquez la Corte confirmó su postura, al menos puso de relieve que la no aplicación del derecho internacional humanitario no suponía su exclusión como herramienta interpretativa. ${ }^{68}$

66 Comisión IDH, 20 de febrero de 1998, Las Palmeras c. Colombia. Informe No 10/98.

67 Corte IDH, 6 de diciembre del 2001, Fondo, Las Palmeras c. Colombia. Serie C, Nº 90.

68 Corte IDH, 25 de noviembre del 2000, Fondo, Bámaca Velásquez.c. Guatemala. Serie C, No 70, párs. 208-209: si la Corte no está dispuesta a declarar responsable a un Estado, desde el punto de vista internacional, por la violación de tratados internacionales que no le confieren competencia alguna para ello, se comprueba que algunos actos u omisiones que infringen los derechos humanos reconocidos en los tratados que sí son aplicables pueden, además, infringir otros instrumentos internacionales de protección de la persona, a semejanza de lo dispuesto en los Convenios de Ginebra de 1949 y, en particular, en el artículo $3^{\circ}$ común. Hay, en efecto, una equivalencia entre el contenido del artículo $3^{\circ}$ de los Convenios de Ginebra y las disposiciones de la Convención Americana, así como de otros instrumentos internacionales de protección que recogen derechos humanos inderogables (como el derecho a la 
La Corte, desde entonces, no ha renunciado a esa aproximación, impregnada por el cosmopolitismo que le prestan las fuentes exteriores a los efectos de interpretación de los derechos garantizados por la Convención. Ya sean los "asuntos colombianos" (sistemáticamente ligados a la guerra) u otros casos que desvelan conflictos pasados tales como la guerra civil que desfiguró a El Salvador entre 1980 y 1991, ${ }^{69}$ la Corte ha utilizado sin pestañear los Convenios de Ginebra para interpretar el contenido y el alcance de los derechos humanos en período de conflicto armado, conforme con el artículo 29b) de la Convención Americana. ${ }^{70}$

En el caso de la Masacre de Mapiripán, por ejemplo, no dudó en recordar los fundamentos de su metodología interpretativa, llegando a basar su análisis en la posición de la Corte Constitucional colombiana. En efecto,

vida y el derecho a no sufrir torturas o tratamientos crueles, inhumanos o degradantes). Por lo tanto, tal y como se puso de manifiesto en el asunto Las Palmeras (2000), las disposiciones pertinentes de los Convenios de Ginebra pueden ser tenidas en cuenta como elementos de interpretación de la Convención Americana.

69 Conforme a la técnica que consiste en situar las violaciones de los derechos humanos en su contexto histórico, la Corte consagra en el caso Serrano Cruz una parte relativa a Hechos probados, donde presenta los Antecedentes y del contexto bistórico (párs. 48.1-48.14), ver Corte IDH, $1^{\circ}$ de marzo del 2005, Fondo y reparaciones, Las hermanas Serrano Cruq c. El Salvador. Serie C, $N^{\circ} 120$. La Corte calificó además, en esa parte, los combates, afirmando que, entre 1980 y 1991, El Salvador estuvo sometido a un conflicto armado interno, en el que se produjeron desapariciones forzadas de personas - cuyas consecuencias fueron objeto de análisis y de discusión por parte de la Comisión de la Verdad para El Salvador, constituida bajo los auspicios de las Naciones Unidas, de la Comisión Interamericana de los Derechos Humanos (pár. 48.1)-. Es en cualquier caso en la sentencia sobre las excepciones preliminares donde recuerda, de forma solemne (para desechar la excepción ratione materiae opuesta por El Salvador) que hay una "complementariedad entre el derecho internacional de los derechos humanos y el derecho internacional humanitario" (pár. 112), una "convergencia" en la que la Corte ha incluso utilizado la técnica de las medidas provisionales para impedir la gravedad y la urgencia que se derivan de un conflicto armado (pár. 113). Por último, la Corte también ha afirmado solemnemente que el Estado no puede oponerse a la plena efectividad de los derechos humanos consagrados en la Convención Americana basándose en la existencia de un conflicto armado que no es internacional. "[La] existencia de un conflicto armado no internacional no exonera al Estado del deber de cumplir sus obligaciones de respeto y de garantía de los derechos consagrados en la Convención Americana de todas las personas que se encuentran bajo su jurisdicción”" (pár. 118), ver Corte IDH, 23 de noviembre del 2004, Excepciones preliminares, Las hermanas Serrano Cruz c. El Salvador. Serie C, No 118.

70 "Artículo 29. Normas de interpretación. Ninguna disposición de la presente Convención puede ser interpretada en el sentido de: [...] b) limitar el goce y ejercicio de cualquier derecho o libertad que pueda estar reconocido de acuerdo con las leyes de cualquiera de los Estados partes o de acuerdo con otra convención en que sea parte uno de dichos Estados". 
insistió en afirmar que el juez constitucional de Bogotá (uno de los más innovadores del continente americano) había integrado el derecho internacional humanitario en el bloque de constitucionalidad, otorgándole el estatuto de ius cogens e imponiendo su respeto a todos los actores estatales y no estatales del conflicto armado... ${ }^{71}$

Igualmente, en el caso de la Masacre de Ituango, la Corte analiza a la luz del Protocolo II del 8 de junio de 1977, adicional a los Convenios de Ginebra, a la vez, el derecho de propiedad (artículo 21 de la Convención Americana) y el derecho a circular (artículo 22). El conjunto de esos elementos, asociados siempre a una apreciación de la jurisprudencia constitucional colombiana, permiten a la Corte de San José afirmar que una "privación grave del uso y disfrute de los bienes" de los habitantes de la localidad de El Aro, ${ }^{72}$ constituye una "violación de los derechos consagrados en el artículo 22, leído de forma conjunta con el artículo 1.1, con respecto a 702 personas desplazadas". 73

Aunque también en el universo europeo encontramos una apertura en cuanto a las fuentes de interpretación, ${ }^{74}$ hay un obstáculo importante que

71 Ad ex., Corte IDH, 7 de marzo del 2005, Fondo y reparaciones, "Masacre de Mapiripán" c. Colombia. Serie C, $\mathrm{N}^{\circ} 134$, pár. 115, donde se cita la Sentencia C-225/95 del 18 de mayo de 1995 de la Corte Constitucional colombiana.

72 Corte IDH, $1^{\circ}$ de julio del 2006, Fondo y reparaciones, Masacre de Ituango c. Colombia. Serie C, $\mathrm{N}^{\circ} 148$, pár. 179. La Corte pone especialmente en evidencia en el párrafo 180 la importancia de los artículos 13 (protección de la población civil) y 14 (protección de los bienes indispensables para la supervivencia de la población civil) del Protocolo II, que prohíben respectivamente "los actos o las amenazas de violencia cuya finalidad principal es aterrorizar a la población civil", así como el hecho "de atacar, destruir, sustraer (...) los bienes indispensables para la supervivencia de la población civil”. En el párrafo 182, la Corte afirma que la intención del incendio y de la destrucción de los hogares de las poblaciones de El Aro era "instaurar el terror y obligarles a desplazarse para obtener una victoria territorial en la lucha contra la guerrilla en Colombia". De esta manera, "la confiscación del ganado y la destrucción de las casas por los paramilitares, llevada a cabo con la colaboración directa de los agentes del Estado, constituye una grave privación del uso y disfrute de los bienes" (pár. 183).

73 Corte IDH, $1^{\circ}$ de julio del 2006, Fondo y reparaciones, Masacre de Ituango c. Colombia. Serie C, $N^{\circ} 148$, pár. 235. Sobre el tema general de los desplazamientos forzados, nos remitiremos a Thiele, B. Litigating against forced evictions under the American Convention on Human Rights. Netherlands Quarterly of Human Rights, 21(3), 2003, pp. 463-477.

74 El Tribunal de Estrasburgo se ha abierto a las fuentes externas de todo género para interpretar el texto convencional europeo. Se trata de una tendencia de fondo, surgida estos últimos años, que recurre tanto a la soft law como a la hard law. La sentencia de la Gran Sala del 28 de noviembre del 2008 Demir et Baykara c. Turquía muestra, por primera vez, de forma muy estructurada y pedagógica, la metodología del TEDH en esta materia (ver especialmente 
sigue suscitando muchas reacciones críticas: la expresa exclusión del Derecho de La Haya y de Ginebra como fuentes externas que permiten mantener viva la interpretación finalista. ${ }^{75}$ ¿Para cuándo un cambio inspirado en la jurisprudencia interamericana? Si, en el importantísimo asunto Serguë Zolotoukbine, ${ }^{76}$ el Tribunal Europeo se ha inspirado expressis verbis en la jurisprudencia de la Corte de San José ${ }^{77}$ combinada con la del Tribunal de Luxemburgo, para orquestar un cambio de envergadura con respecto al significado del principio non bis in idem, es posible pensar que una actitud comparable alcanzará, algún día, al papel interpretativo correspondiente al Derecho de Ginebra...

Ese cambio sería aún más deseable si se tiene en cuenta la crítica, aunque sea indirecta, que la Corte Interamericana ha dirigido a su homóloga europea. Ha afirmado, en efecto, en varias ocasiones, que, incluso si el criterio de proporcionalidad es un criterio importante y útil cuando se trata de determinar el campo de aplicación de un derecho individual, no es un

los párrafos 60-86), Sudre, F. L'interprétation constructive de la liberté syndicale au sens de l'article 11 de la Convention EDH. JCP Ed. Gen., (5), 28 de enero del 2009.

75 El Tribunal Europeo se niega, sin embargo, a aplicar esta apertura al derecho internacional humanitario, ya que no ha querido integrarlo, de manera expresa, en su técnica de interpretación finalista, ver, ad ex., TEDH, 25 de febrero del 2005, Issaiëva c. Rusia, ver Flauss, J.-F. \& Cohen-Jonathan, G. Cour européenne des droits de l'homme et Droit International général. AFDI, 2005, pp. 676-677. Sobre la situación en Chechenia, ver Blanc Artemir, A. El conflicto de Chechenia: implicaciones en el ámbito del derecho internacional humanitario y de los derechos humanos. In: Soroeta, J. (ed.). Conflictos y protección de derechos humanos en el orden internacional. Cursos de derechos humanos de Donostia-San Sebastián. Vol. VI. Universidad del País Vasco, 2006, pp. 67-148.

76 TEDH, G. S., 10 de febrero del 2009, Sergueï Zolotoukhine c. Rusia, párrafos 39-40 (parte "En fait" de la sentencia) y párrafo 79 (parte "En droit" de la sentencia). Es preciso, en cualquier caso, mencionar aquí que es la combinación de la jurisprudencia comunitaria (TJCE) con la jurisprudencia interamericana (Corte IDH) la que permitió al TEDH afirmar en el párrafo 82 que "por consiguiente, el artículo $4^{\circ}$ del Protocolo 7 debe entenderse en el sentido de que prohíbe perseguir o juzgar a una persona por una segunda 'infracción' siempre que esta tenga su origen en hechos idénticos o hechos que son, sustancialmente, los mismos" (la traducción es de las autoras).

77 Corte IDH, 17 de septiembre de 1997, Loayza Tomayo c. Perú. Serie C, No 33, pár. 66. El juez de San José ponía de manifiesto la redacción del artículo 8.4 de la Convención Americana que, contrariamente a otros instrumentos internacionales (como el artículo 14.7 del Pacto IDCP), emplea la expresión mismos hechos, la cual es más amplia y, por lo tanto, más favorable para la víctima. 
criterio suficientemente adaptado para hacer frente a operaciones militares y a situaciones de violencia generalizada... ${ }^{78}$

\section{B) El derecho de los regímenes de excepción}

Los regímenes autoritarios latinoamericanos no se han privado, a lo largo de los años setenta y ochenta, de abusar e instrumentalizar la teoría de las circunstancias excepcionales. ${ }^{79}$ El jurista uruguayo Héctor Gros Espiell, que fue uno de los presidentes de la Corte Interamericana (1989-1990), lo relata de manera muy clara en uno de sus cursos en la Academia de La Haya, donde afirmó: "Las medidas excepcionales, que no deben de ninguna manera conducir ni a la suspensión de la Constitución ni a la supresión del Estado de Derecho $(. . . / \ldots)$ han servido en América Latina, en múltiples ocasiones, para abolir la Constitución y derribar los gobiernos legítimos con el fin de usurpar el poder. Los estados de excepción han sido utilizados, con frecuencia, para disimular golpes de Estado o como cortinas para ocultar los comienzos de regímenes tiránicos". ${ }^{80}$

Los hechos son inapelables y muestran lo que durante mucho tiempo ha formado parte de la cultura política de la excepción en el seno del continente americano. Si su uso fue y puede todavía ser algo corriente en el continente, su puesta en práctica no es, sin embargo, fácil. En efecto, la multitud de expresiones utilizadas en derecho constitucional -“estado de sitio”, "estado de urgencia”, "estado de guerra", "estado de excepción”- no parecen muy pertinentes, prefiriéndose la doctrina internacional, que engloba todas las posibilidades bajo el término "estado de urgencia" o de "excepción". ${ }^{81}$ Aun así, definir el estado de excepción no es cosa fácil. La Convención

78 Corte IDH, 31 de enero del 2006, Fondo y reparaciones, Masacre de Pueblo Bello c. Colombia. Serie C, No 140, pár. 133. Ver Burgorgue-Larsen \& Úbeda de Torres, Les grandes décisions..., op. cit., p. 383.

79 Un análisis de la acción pionera de la Comisión Interamericana frente a esas situaciones de excepción se contiene en Fitzpatrick, J. States of emergency in the Inter-American Human Rights System. In: Harris, D. J. \& Livingston, S. (eds.). The Inter-American System of Human Rights. Oxford: Oxford University Press, 2004, pp. 371-394.

80 Gros Espiell, H. La Convention américaine et la Convention européenne des droits de l'homme. Analyse comparative. RCADI, VI(218), 1989, p. 296.

81 Úbeda de Torres, A. Democracia y derechos humanos en Europay en América. Estudio comparado de los sistemas europeo e interamericano de protección de los derechos humanos. Madrid: Editorial Reus, 2007, pp. 579 y ss. 
Americana no contiene una definición acorde con las circunstancias ${ }^{82}$ y parece complejo, incluso imposible, crear una categoría única en la que englobar situaciones tan heterogéneas. ${ }^{83}$

El artículo 27.1 de la Convención Americana ${ }^{84}$ (al igual que el artículo 15 del Convenio Europeo de Derechos Humanos) prevé la posibilidad que tienen los Estados de no respetar las obligaciones convencionales en nom-

82 Aunque el artículo 27 menciona los casos de guerra, de peligro público o de cualquier otra situación..., lo que demuestra la voluntad de los autores de la Convención de no definir a priori las situaciones contempladas para no ser demasiado limitativos.

83 De esta noción se desprenden dos perspectivas posibles: la primera definiría el estado de excepción en función de sus efectos sobre el respeto de los derechos fundamentales y de las obligaciones estatales. Se trataría, pues, de vincular el concepto a las circunstancias excepcionales que lo rodean, opuestas a la situación de “normalidad". La segunda posibilidad sería establecer la existencia de una serie de condiciones formales necesarias que permitirían distinguir los estados de iure, abiertamente proclamados y que se adaptan al orden jurídico, y los estados de facto, que existen incluso aunque el Estado no los reconozca como tales, ver Fitzpatrick, J. Human rights in crisis. The International System for Protecting Rights during States of Emergency. Philadelphia: University of Pennsylvania Press, 1994, pp. 4-18. Las dos definiciones presentan carencias importantes. La primera de ellas, la definición material, precisaría establecer las causas que permiten declarar que existe un estado de urgencia y, de esa manera, distinguir situaciones que, aunque excepcionales, no podrían llevar a la adopción de medidas extremas por parte de los gobiernos. La segunda definición, más formal, dependería, para poder existir, del reconocimiento por parte del Estado de la situación, con los riesgos que eso lleva consigo; además, exigiría igualmente establecer diferentes niveles de "gravedad" para desarrollar los poderes estatales extraordinarios. La relatora de la Subcomisión de las Naciones Unidas para la Prevención y la Protección de las Minorías, Nicole Questiaux, hizo a principio de los años ochenta un estudio de los estados de excepción existentes en el mundo. Se mencionaron, entre las causas de urgencia, las catástrofes naturales, el subdesarrollo y la guerra. Estableció, frente a la exigencia de las condiciones estrictas de forma, una tipología de las diferentes posibilidades de desviación existentes: la urgencia formal no notificada a los órganos internacionales de control; la urgencia permanente, basada en prolongaciones continuas de las condiciones formales de su existencia; la urgencia compleja, que implica una confusión de regímenes jurídicos, suspende una parte de las garantías constitucionales y dicta un gran número de decretos, y, por último, la urgencia institucionalizada, en la que la extensión del régimen transitorio se basa en el objetivo de la vuelta a la normalidad democrática; ver Questiaux, N. Study of implications for buman rights of recent developments concerning situations known as status of siege or emergency. UN Doc. E/CN.4/Sub.2/1982/15, 1982.

84 Se encuentra encuadrado bajo el título de Suspensión de garantías y redactado de la manera siguiente: "En caso de guerra, de peligro público o de otra emergencia que amenace la independencia o seguridad del Estado parte, éste podrá adoptar disposiciones que, en la medida y por el tiempo estrictamente limitados a las exigencias de la situación, suspendan las obligaciones contraídas en virtud de esta Convención, siempre que tales disposiciones no sean incompatibles con las demás obligaciones que les impone el derecho internacional y 
bre, precisamente, de la preservación de la democracia liberal. Este artículo entrega a los Estados la facultad de apreciar la existencia de un conjunto de circunstancias que, suponiendo una amenaza para el país, les permite "suspender", de forma provisional, ciertas garantías. La identificación de las circunstancias excepcionales que permiten poner entre paréntesis las garantías constitucionales no es cosa fácil; en cualquier caso, la Corte ha tratado de definirlas.

Las circunstancias, pues, que permiten que la "excepción" entre en juego son, como señala la primera frase del párrafo 1 del artículo 27, "la guerra, el peligro público u otra emergencia que amenace la independencia o la seguridad del Estado parte". Este enfoque, parcialmente casuístico, presenta algunos inconvenientes relacionados con la incertidumbre y la falta de precisión de los conceptos empleados. La doctrina ha criticado diferentes aspectos de la fórmula escogida, afirmando que la guerra y el peligro público aparecen como subconjuntos distintos de la tercera categoría de "excepción", que se refiere a otras emergencias.

Además, la amenaza a la independencia o a la seguridad del Estado no se refiere de forma global a la vida o a la supervivencia del Estado, sino que deja abierta la posibilidad de que la justificación sea más deseada que realmente excepcional. ${ }^{85} \mathrm{Si}$ la primera amenaza (a la independencia), que es, sobre todo, una demostración de la fuerza de atracción del principio de no intervención en el sistema interamericano, parece tener su origen en actividades externas al funcionamiento autónomo de las instituciones del Estado, la segunda (la amenaza a la seguridad) es aún más peligrosa, ya que está unida a la tristemente célebre doctrina de la seguridad nacional, que fue sobreexplotada por los regímenes dictatoriales de los años setenta y ochenta. ${ }^{86}$ La interpretación que se hace de esta expresión por las autoridades estatales exige, por lo tanto, un control internacional riguroso para vigilar la restricción de los derechos.

Todos estos elementos han sido objeto de análisis por la Comisión y la jurisprudencia de la Corte. En uno de sus informes relativos a Colombia, la Comisión Interamericana afirmó que las condiciones del estado de sitio

no entrañen discriminación alguna fundada en motivos de raza, color, sexo, idioma, religión u origen social".

85 Úbeda de Torres, A. Democracia y derechos humanos en Europa y en América, op. cit., p. 585.

86 Zovatto, D. Los estados de excepción y los derechos bumanos en América Latina. Caracas/San José: IIDH, Editorial Jurídica Venezolana, 1990, pp. 51 y ss. 
"vigente en forma casi ininterrumpida por varias décadas, se han traducido en una situación endémica que ha afectado, en cierta medida, el pleno goce de las libertades y derechos ciudadanos, por cuanto, entre otros aspectos, se ha permitido el juzgamiento de civiles por tribunales militares".

La Comisión recomienda al Estado que ponga fin a esta situación, ${ }^{87}$ una constante que se repite en sus análisis, a la vista de que el estado de urgencia debe ser excepcional y no puede prolongarse ni constituir un medio que permita justificar violaciones constantes de los derechos humanos. ${ }^{88}$ Apoyándose en esta interpretación restrictiva del artículo 27.1 de la Convención Americana (un punto de vista compartido por la jurisprudencia europea), ${ }^{89}$ la Corte Interamericana ha puntualizado que la suspensión de las garantías es ilegal cuando se utiliza para restringir los límites indispensables de los derechos esenciales de la persona. ${ }^{90}$

Así mismo, la Corte ha tomado la precaución, en el asunto Zambrano $V$ élez, de presentar los modos de utilización de la fuerza armada para hacer frente a perturbaciones sociales graves que dan lugar a fenómenos de delincuencia masiva. Además de comprobar que el Estado ecuatoriano no había respetado, en el caso concreto, ninguna de las condiciones formales exigidas por el punto 3 del artículo $27,{ }^{91}$ la Corte señaló que la intervención

87 Comisión IDH. Informe especial sobre Colombia. OEA/Ser.L/V/II.53, doc. 22, 30 de junio de 1981, conclusiones, segundo párrafo.

88 En su informe sobre Chile, inmediatamente posterior al golpe de Estado y al acceso al poder del general Pinochet, la Comisión afirmó que ella no cuenta como atentado a los derechos humanos las pérdidas de vidas humanas sufridas por una y otra parte a lo largo de los días iniciales de ese proceso, teniendo así por objeto "evitar todo juicio de valor" que le obligaría a pronunciarse sobre la legalidad o ilegalidad y sobre las bases de la gestión del régimen precedente. En cualquier caso, ello no le ha impedido comprobar que con las violaciones reiteradas de los derechos humanos, Chile vulneraba los derechos reconocidos en la Declaración Americana, ver Comisión IDH, Informe sobre la situación de los derechos humanos en Chile. OEA/Ser.L/V/II.34, doc. 21, 25 de octubre de 1974, capítulo XVI, conclusiones, párrafo II.

89 Resulta interesante destacar que se refiere, en la sentencia Zambrano Vélez (pár. 46, ver nota 91), a la sentencia Lawless c. Irlanda, de $1^{\circ}$ de julio de 1961 , Serie A, № 3, pár. 28, para recordar que un estado de excepción debe a) establecerse en un período excepcional de crisis o de urgencia, b) que afecte a toda la población y c) que constituya una amenaza para la vida organizada de la sociedad.

90 Corte IDH, 6 de octubre de 1987, Opinión, Garantias judiciales en estados de emergencia (arts. 8, 25 y 27.2 de la Convención Americana de Derechos Humanos). Serie A, No 9, párs. 38-40.

91 Corte IDH, 4 de julio del 2007, Fondo, Zambrano Vélezy otros c. Ecuador. Serie C, No 165 , párs. 69 y ss. El apartado 3 del artículo 27 dice así: "Todo Estado parte que haga uso del 
militar como medio de control de las protestas sociales, de los desórdenes internos, de la violencia interna y de las situaciones excepcionales debía ser extraordinariamente prudente. ${ }^{92}$

En este asunto, la Corte Interamericana no solo ha exigido el estricto control de las actividades estatales en el marco de tensiones y conflictos, sino que ha controlado también la proporcionalidad entre la gravedad de la situación y las medidas tomadas por el Estado. ${ }^{93}$ Para ello se inspiró, una vez más, en fuentes externas al sistema interamericano, en esa ocasión en las Normas de Turku que establecen los principios humanitarios mínimos aplicables en estados de excepción. ${ }^{94}$

El punto 2 del artículo $27^{95}$ insiste en los límites de la excepción, enumerando una lista de once derechos que no pueden suspenderse en ningún caso. ${ }^{96}$ Desde el punto de vista de la "jerarquía” que se deriva del principio democrático, la Convención Americana mantiene, incluso en situación de excepción, su "patrimonio democrático común", en la medida en que los derechos electorales son protegidos, mientras que la misma protección no existe en el Convenio Europeo. ${ }^{97}$

derecho de suspensión deberá informar inmediatamente a los demás Estados partes en la presente Convención, por conducto del Secretario General de la Organización de los Estados Americanos, de las disposiciones cuya aplicación haya suspendido, de los motivos que hayan suscitado la suspensión y de la fecha en que haya dado por terminada tal suspensión".

92 Ibíd., pár. 51.

93 Ibíd., párs. 47-52; ver también Úbeda de Torres, A. L'Etat de droit dans la jurisprudence de la Cour interaméricaine des droits de l'homme. In: SFDI. L'Etat de droit en Droit international. Coloquio Anual de la Sociedad Francesa de Derecho Internacional. París: Pedone, 2009, pp. 185 y ss.

94 Normas humanitarias aplicables en período de estado de excepción o "Normas de Turku", adoptadas en Finlandia y revisadas en Oslo en 1994.

95 "La disposición precedente no autoriza la suspensión de los derechos determinados en los siguientes artículos: $3^{\circ}$ (derecho al reconocimiento de la personalidad jurídica); $4^{\circ}$ (derecho a la vida); $5^{\circ}$ (derecho a la integridad personal); $6^{\circ}$ (prohibición de la esclavitud y servidumbre); $9^{\circ}$ (principio de legalidad y de retroactividad); 12 (libertad de conciencia y de religión); 17 (protección a la familia); 18 (derecho al nombre); 19 (derechos del niño); 20 (derecho a la nacionalidad) y 23 (derechos políticos), ni de las garantías judiciales indispensables para la protección de tales derechos".

96 Es interesante señalar que la lista de los derechos inderogables en el Convenio Europeo es bastante menor; el artículo 15 sólo menciona los derechos protegidos en los artículos $2^{\circ}$, $3^{\circ}$ y $7^{\circ}$.

97 Tavernier, P. L'article 15. In: Pettiti, L.-E.; Decaux, E. \& Imbert, P.-H. La Convention européenne des droits de l'bomme. Commentaire article par article. Paris: Economica, 1995, p. 499. 
Si el principio democrático parece encontrarse más sólidamente protegido en la Convención Americana, ello se refuerza por la protección del Estado de derecho que prevé el sistema interamericano. Tal protección ha permitido una interpretación privilegiada por parte de la Corte Interamericana en dos importantes opiniones consultivas, la del 30 de enero de 1987 y la del 6 de octubre de $1988 .{ }^{98}$ La primera se refería al recurso específico de bábeas corpus que se recoge en el artículo 7.6 y al recurso genérico de amparo del artículo 25.1, ${ }^{99}$ mientras que la segunda se planteó a instancias de Uruguay, quien preguntó si era posible la suspensión de las garantías de los artículos $8^{\circ}$ y 25.1 de la Convención durante el período de vigencia del estado de emergencia. ${ }^{100}$

Las bases de estos dos dictámenes son prácticamente idénticas, ya que en ambas se trataba de establecer si la expresión "garantías indispensables" del artículo 27.2 in fine incluía las vías de los recursos mencionadas más arriba. Dicho de otra manera, ¿los períodos de excepción autorizan la suspensión de las garantías judiciales? Basándose en una argumentación que mezcla historia reciente del subcontinente con argumentos jurídicos propios de la sociedad democrática, la Corte de San José estimó que no era posible, en el marco de un Estado de derecho, suspender las garantías judiciales de los artículos 7.6, 8.1 y 25.1, necesarias para asegurar la plenitud del ejercicio de los derechos y de las libertades. La Corte confirmó en el ejercicio de su competencia contenciosa la existencia de esta prohibición establecida en la Convención consustancial al respeto del principio democrático. ${ }^{101}$

El sistema interamericano ha sido el primero en el campo de la protección de los derechos humanos en enfrentarse a violaciones masivas de los derechos. Los golpes de Estado de caudillos de todo tipo han destruido numerosas

98 Burgorgue-Larsen \& Úbeda de Torres, Les grandes décisions..., op. cit., espec. pp. 667 y 707.

99 Corte IDH, 30 de enero de 1987, Opinión consultiva, El bábeas corpus bajo suspensión de garantías. Serie A, $\mathrm{N}^{\circ} 8$.

100 Corte IDH, 6 de octubre de 1987, Opinión consultiva, Las garantías judiciales en estados de emergencia. Serie A, No 9.

101 Corte IDH, 16 de agosto del 2000, Fondo, Durandy Ugarte c. Perú. Serie C, No 68; Corte IDH, 18 de agosto del 2000, Fondo, Cantoral Benavides c. Perú. Serie C, № 69; Corte IDH, 8 de julio del 2004, Fondo y reparaciones, Hermanos Gómez Paquiyauri c. Perú. Serie C, No 11. 
vidas y desmembrado un considerable número de sociedades. ${ }^{102}$ La doctrina de la Comisión y la jurisprudencia de la Corte se han desarrollado sobre ese terreno; su aportación al derecho internacional de los derechos humanos, así como al derecho internacional humanitario, es fundamental y no puede sino alimentar las reflexiones que en la actualidad se hacen acerca de la complementariedad de estas dos grandes ramas del Derecho Internacional

\section{Bibliografía}

Andreani, G. La guerre contre le terrorisme. Le piege des mots. AFRI, 2003, pp. 102-114.

Asturias, Miguel Ángel. El señor Presidente. Buenos Aires-Madrid: AlianzaLosada, 1987 (1 ${ }^{\mathrm{a}}$ ed., 1948), 306 p.

Bannelier, K.; Christakis, T.; Corten, O. \& Delcourt, B. (dirs.). Le droit international face au terrorisme. Paris: Pedone, 2002, 356 p.

Blanc Artemir, A. El conflicto de Chechenia: implicaciones en el ámbito del derecho internacional humanitario y de los derechos humanos. In: Soroeta, J. (ed.). Conflictos y protección de derechos humanos en el orden internacional. Cursos de derechos humanos de Donostia-San Sebastián. Vol. VI. Universidad del País Vasco, 2006, pp. 67-148.

Bourgorgue-Larsen, L. Les Etats Unis d'Amérique et la justice internationale. Entre l'utilisation et l'instrumentalisation du Droit International. In: Ben Achour, R. \& Laghmani, S. (dirs.). Le Droit International a la croisée des chemins. Force du droit et force de la force. Paris: Pedone, 2004, pp. 233-269.

Bribosia, E.; Scheeck, L. \& Úbeda de Torres, A. (eds.). L'Europe des Cours. Bruxelles: Bruylant, en prensa.

Burgorgue-Larsen, L. \& Úbeda de Torres, A. Les grandes décisions de la Cour interaméricaine des droits de l'homme. Bruxelles: Bruylant, 2008, spec. pp. 270-303 (commentaire $N^{0} 11$ ).

Burgorgue-Larsen, L. Le principe et d'égalité et de non-discrimination dans la jurisprudence interaméricaine des droits de l'homme. In: Sudre, F. \& Surrel, H. (dirs.). Le droit à la non-discrimination au sens de la Convention européenne des droits de l’homme. Bruxelles: Bruylant, 2008.

102 La trágica realidad de los regímenes autoritarios ha dado ocasión a grandes autores de la literatura hispanoamericana de producir obras tan espléndidas como desesperadas. Remitiremos aquí a título de ejemplo la novela magistral de Miguel Ángel Asturias, El señor Presidente, Buenos Aires-Madrid: Alianza-Losada, 1987 (1ª edición, 1948), 306 p. 
- Les nouvelles tendances de la jurisprudence interaméricaine des droits de l'homme. Cursos de Derecho Internacionaly Relaciones Internacionales de Vitoria-Gasteiz.2008. Bilbao; 2009, en prensa.

Dinges, J. Les Années Condor. Comment Pinochet et ses alliés ont propagé le terrorisme sur trois continents. Paris: La Découverte, 2005.

Droege, C. Efective affinities? Human rights and humanitarian law. IRRCRICR, September 2008, pp. 501-548.

Duffy, H. Human rights litigation and the "war of terror". Revue internationale de la Croix Rouge, 80(871), septiembre 2008, pp. 573-597.

Dufour, J-L. Les crises internationales. De Pékin (1900) à Bagdad (2004). Paris: Ed. Complexes, 2004, 326 p.

Farrior, S. State responsability for human rights abuses by non State actors. American Society of International Law Proceedings, (92), 1998.

Fitzpatrick, J. Human rights in crisis. The International System for Protecting Rights during States of Emergency. Philadelphia: University of Pennsylvania Press, 1994.

- States of emergency in the Inter-American Human Rights System. In: Harris, D. J. \& Livingston, S. (eds.). The Inter-American System of Human Rights. Oxford: Oxford University Press, 2004, pp. 371-394.

Flauss, J.-F. \& Cohen-Jonathan, G. Cour européenne des droits de l'homme et Droit International général. AFDI, 2005.

Fleck, D. The handbook of humanitarian law in armed conflict. Oxford: Oxford University Press, 1995.

Garapon, A. \& Allard, J. Les juges dans la mondialisation. La nouvelle révolution du droit. Paris: Editions du Seuil et La République des idées, 2005, 96 p.

Gilbert Guillaume, Les grandes crises internationales et le droit. Paris: Seuil, 1994, 318 p.

Gros Espiell, H. La Convention américaine et la Convention européenne des droits de l'homme. Analyse comparative. RCADI, VI(218), 1989.

Grossman, C. The Velásquez Rodríguez Case: the development of the InterAmerican Human Rights System. International Law Stories, Foundation Press, 2007, pp. 77-113.

La juridictionnalisation du Droit International. Paris: Pedone, SFDI, 2003.

MacCarthy, C. Human Rights and the laws of war under the American Convention on Human Rights. European Human Rights Law Review, 6, 2008, pp. 762-778.

Martin, F. Application du Droit International Humanitaire par la Cour interaméricaine des droits de l'homme. RICR, 83(844), 2003, pp. 1037-1066. 
Mélanges en l’honneur du président Bruno Genevois. Le dialogue des juges. Paris: Dalloz, 2009.

Melo, A. \& Raffin, M. Obsesiones y fantasmas de la Argentina. El antisemitismo, Evita, los desaparecidos y Malvinas en la ficción literaria. Buenos Aires: Ediciones del Puerto, 2005, 221 p.

Meyrowitz, H. Le droit de la guerre et les droits de l'homme. RDP, 5, 1972.

Momtaz, D. Les règles et les institutions du Droit International Humanitaire à l'épreuve des conflits armés récents. Leiden-Boston: Centre d'étude et de recherche de droit international et de relations internationales 2007, Martinus Nijhoff Publishers, 2008, 227 p.

Nieto, R. ¿Hay o no hay conflicto armado en Colombia? Anuario Colombiano de Derecho Internacional, Año 1, No 1, 2008, pp. 139-159.

Oisel, M. Juger les crimes de masse. La mémoire collective et le droit. Paris: Seuil, 2006, 453 p.

Pérez González, M. \& Rodríguez-Villasante, J-L. El caso de los detenidos de Guantánamo ante el derecho internacional humanitario y de los derechos humanos. Revista Española de Derecho Internacional, 54(1), 2002, pp. 11-40.

Pinto, M. L'Amérique latine et le traitement des violations massives des droits de l'homme. Paris: Pedone, 2007, 96 p.

- Responsabilidad internacional por la violación de los derechos humanos y los entes no estatales. Héctor Gros Espiell Amicorum Liber. Bruxelles: Bruylant, 1997, pp. 1155-1173.

Questiaux, N. Study of implications for buman rights of recent developments concerning situations known as status of siege or emergency. UN Doc. E/CN.4/ Sub.2/1982/15, 1982.

Salmon, J. Dictionnaire de droit international public. Bruxelles: Bruylant, 2001.

Sudre, F. L'interprétation constructive de la liberté syndicale au sens de l'article 11 de la Convention EDH. JCP Ed. Gen., (5), 2009.

Suter, K. D. An inquiry into the meaning of the phrase of "human rights in armed conflicts". Revue de Droit Pénal Militaire et de Droit de la Guerre, 15(3-4), 1976.

Tavernier, P. L'article 15. In: Pettiti, L.-E.; Decaux, E. \& Imbert, P.-H. La Convention européenne des droits de l'homme. Commentaire article par article. Paris: Economica, 1995.

Thiele, B. Litigating against forced evictions under the American Convention on Human Rights. Netherlands Quarterly of Human Rights, 21(3), 2003, pp. 463-477. 
Úbeda de Torres, A. Democracia y derechos bumanos en Europa y en América. Estudio comparado de los sistemas europeo e interamericano de protección de los derechos humanos. Madrid: Editorial Reus, 2007.

- L'Etat de droit dans la jurisprudence de la Cour interaméricaine des droits de l'homme. In: SFDI. L'Etat de droit en Droit international. Coloquio Anual de la Sociedad Francesa de Derecho Internacional. París: Pedone, 2009.

Zegveld, L. La Comisión Interamericana de Derechos Humanos y el derecho internacional humanitario: comentario acerca del caso "La Tablada". RICR, No 147, septiembre 1998, pp. 547-554.

Zovatto, D. Los estados de excepción y los derechos humanos en América Latina. Caracas/San José: IIDH, Editorial Jurídica Venezolana, 1990.

\section{Informes y decisiones judiciales}

CICR, ¿Cuál es la definición de "conflicto armado" según el derecho internacional bumanitario? Dictamen de marzo del 2008.

Comisión IDH, Informe sobre la situación de los derechos bumanos en Cbile. OEA/ Ser.L/V/II.34, doc. 21, 25 de octubre de 1974.

—. Informe especial sobre Colombia. OEA/Ser.L/V/II.53, doc. 22, 30 de junio de 1981.

- 30 de septiembre de 1997, Arturo Ribón Ávila c. Colombia, asunto $\mathrm{N}^{\circ}$ 11.142, Informe $\mathrm{N}^{\circ} 26 / 97$.

. 18 de noviembre de 1997, Abella (asunto llamado "La Tablada") $c$. Argentina, asunto $\mathrm{N}^{\circ} 11.137$, informe $\mathrm{N}^{\circ} 55 / 97$.

. 20 de febrero de 1998, Las Palmeras c. Colombia. Informe No 10/98.

Corte IDH, opinión consultiva de 24 de septiembre de 1982, "Otros tratados" objeto de la función consultiva de la Corte (articulo 64 de la $C A D H$ ). Serie A, $\mathrm{N}^{\circ} 1$.

- 30 de enero de 1987, El hábeas corpus en período de suspensión de garantías. Serie A, $\mathrm{N}^{\circ} 8$.

- 6 de octubre de 1987, Opinión consultiva, Las garantías judiciales en estados de emergencia. Serie A, $\mathrm{N}^{\circ} 9$.

- 8 de diciembre de 1995, Fondo, Caballero Delgado y Santana c. Colombia. Serie C, $\mathrm{N}^{\circ} 22$.

17 de septiembre de 1997, Loayza Tomayo c. Perú. Serie C, No 33.

. 30 de mayo de 1999, Fondo y reparaciones, Castillo Petruzzi c. Perú. Serie $C, \mathrm{~N}^{\circ} 52$. 
19 de noviembre de 1999, Fondo, Villagrán Morales y otros c. Guatemala. Serie $\mathrm{C}, \mathrm{N}^{\mathrm{o}} 63$.

. 4 de febrero del 2000, Excepciones preliminares, Las Palmeras c. Colombia. Serie C, No 67.

- 16 de agosto del 2000, Fondo, Durandy Ugarte c. Perú. Serie C, No 68. . 18 de agosto del 2000, Fondo, Cantoral Benavides c. Perú. Serie C, $\mathrm{N}^{\circ} 69$.

_. 25 de noviembre del 2000, Fondo, Bámaca Velásquez. c. Guatemala. Serie C, $\mathrm{N}^{\mathrm{o}} 70$.

- 6 de diciembre del 2001, Fondo, Las Palmeras c. Colombia. Serie C, $\mathrm{N}^{\circ} 90$.

- 6 de febrero del 2001, Ivcher Bronstein c. Perú. Serie C, No 74.

31 de agosto del 2001, Fondo y reparaciones, Comunidad Mayagna (Sumo) Awas Tigni c. Nicaragua. Serie C, No 79.

— 17 de septiembre del 2003, Estatuto jurídico y derechos de los trabajadores migrantes indocumentados. Serie A, No 18.

—. 23 de noviembre del 2003, Fondo y reparaciones, Myrna Mack Chang c. Guatemala. Serie C, No 101.

- 5 de julio del 2004, Fondo y reparaciones, Diecinueve comerciantes $c$. Colombia. Serie C, No 109.

—. 8 de julio del 2004, Fondo y reparaciones, Hermanos Gómez Paquiyauri c. Perú. Serie C, No 11.

- 7 de septiembre del 2004, Tibi c. Ecuador. Serie C, No 114.

. 23 de noviembre del 2004, Excepciones preliminares, Las hermanas Serrano Cruzc. El Salvador. Serie C, No 118.

- $1^{\circ}$ de marzo del 2005, Fondo y reparaciones, Las hermanas Serrano Cruzc. El Salvador. Serie C, No 120.

- 7 de marzo del 2005, Fondo y reparaciones, "Masacre de Mapiripán" c. Colombia. Serie C, No 134.

—. 23 de junio del 2005, Fondo y reparaciones, Yatama c. Nicaragua. Serie C, $\mathrm{N}^{\mathrm{o}} 127$.

- 8 de septiembre del 2005, Fondo y reparaciones, Las niñas Yean y Bosico c. República Dominicana. Serie C, No 130.

—. 12 de septiembre del 2005, Fondo, "Masacre de Mapiripán” c. Colombia. Serie C, No 134.

- 22 de noviembre del 2005, Fondo y reparaciones, Palamara Iribarne c. Chile. Serie C, No 135 .

- 31 de enero del 2006, Fondo y reparaciones, Masacre de Pueblo Bello c. Colombia. Serie C, No 140 . 
- $.1^{\circ}$ de julio del 2006, Excepciones preliminares, fondo y reparaciones, Masacre de Ituango c. Colombia. Serie C, No 148.

- 4 de julio del 2006, Fondo y reparaciones, Ximenes Lopes c. Brasil. Serie C, $\mathrm{N}^{\mathrm{o}} 149$.

- 19 de septiembre del 2006, Fondo y reparaciones, Claude Reyes c. Chile. Serie C, No 151.

- 22 de septiembre del 2006, Fondo y reparaciones, Goiburú c. Paraguay. Serie $\mathrm{C}, \mathrm{N}^{\circ} 153$.

- 26 de septiembre del 2006, Fondo y reparaciones, Almonacid Arellano y otros c. Chile. Serie C, No 154.

- 25 de noviembre del 2006, Fondo y reparaciones, Prison Miguel Castro Castro c. Perú. Serie C, No 160.

- 29 de noviembre del 2006, Fondo y reparaciones, La Cantuta c. Perú. Serie C, $\mathrm{N}^{\mathrm{o}} 162$.

- 11 de mayo del 2007, Fondo y reparaciones, Masacre de la Rochela $c$. Colombia. Serie C, No 163.

. 4 de julio del 2007, Fondo y reparaciones, Escué Zapata c. Colombia. Serie C, No 165.

- 4 de julio del 2007, Fondo y reparaciones, Zambrano Vélez.c. Ecuador. Serie C, No 165.

- 2 de mayo del 2008, Fondo y reparaciones, Kimel c. Argentina. Serie C, $\mathrm{N}^{\mathrm{o}} 177$.

- 6 de mayo del 2008, Excepciones preliminares y Fondo, Salvador Chiriboga c. Ecuador. Serie C, No 179.

- 6 de agosto del 2008, Excepciones preliminares, Fondo y reparaciones, Castañeda Gutman c. México. Serie C, No 184.

- 12 de agosto del 2008, Excepciones preliminares, Fondo y reparaciones, Heliodoro Portugal c. Panamá. Serie C, No 186.

- 26 de noviembre del 2008, Fondo y reparaciones, Tiu Tojin c. Guatemala. Serie C, No 190.

- 27 de noviembre del 2008, Fondo y reparaciones, Ticona Estraday otros c. Bolivia. Serie C, No 191.

- 27 de noviembre del 2008, Fondo y reparaciones, Valle Jaramillo y otros c. Colombia. Serie C, No 192.

- 27 de enero del 2009, Fondo y reparaciones, Tristán Donoso c. Panamá. Serie C, No 193.

Corte Suprema de los Estados Unidos, 28 de junio del 2004, Hamdi v. Rumsfeld, $\mathrm{N}^{\circ} 03 / 6696$.

—. 28 de junio del 2004, Rasul v. Bush, No 03/334. 
TEDH, 28 de octubre de 1998, Osman c. Reino Unido.

- 28 de marzo del 2000, Kiliç c. Turquía.

. 25 de febrero del 2005, Issaiëva c. Rusia.

. 10 de febrero del 2009, Sergueï Zolotoukhine c. Rusia.

TIJ, Dictamen de 8 de julio de 1996, La legalidad de la amenaza o el empleo de armas nucleares. Rec. CIJ 1996.

- Dictamen de 9 de julio del 2004, Consecuencias jurídicas de la construcción de un muro en el territorio palestino ocupado. Rec. CIJ 2004.

.19 de diciembre del 2005, República Democrática del Congo c. Uganda. Rec. CIJ 2005. 